\title{
A pre-crisis vs. crisis analysis of peripheral EU stock markets by means of wavelet transform and a nonlinear causality test
}

\author{
J. M. Polanco-Martínez*a,b, J. Fernández-Macho ${ }^{c}$, M. B. Neumann ${ }^{\text {a,d }}$, S.H. Faria ${ }^{\text {a,d }}$ \\ ${ }^{a}$ Basque Centre for Climate Change - BC3, 48940 Leioa, Spain \\ ${ }^{b}$ UMR EPOC CNRS 5805, University of Bordeaux, 33615 Pessac, France \\ ${ }^{c}$ Department of Econometrics and Statistics, University of the Basque Country, 48015 Bilbao, Spain \\ ${ }^{d}$ IKERBASQUE, Basque Foundation for Science, 48013 Bilbao, Spain
}

\begin{abstract}
This paper presents an analysis of EU peripheral (so-called PIIGS) stock market indices and the S\&P Europe 350 index (SPEURO), as a European benchmark market, over the pre-crisis (2004-2007) and crisis (2008-2011) periods. We computed a rolling-window wavelet correlation for the market returns and applied a non-linear Granger causality test to the wavelet decomposition coefficients of these stock market returns. Our results show that the correlation is stronger for the crisis than for the pre-crisis period. The stock market indices from Portugal, Italy and Spain were more interconnected among themselves during the crisis than with the SPEURO. The stock market from Portugal is the most sensitive and vulnerable PIIGS member, whereas the stock market from Greece tends to move away from the European benchmark market since the 2008 financial crisis till 2011. The non-linear causality test indicates that in the first three wavelet scales (intraweek, weekly and fortnightly) the number of uni-directional and bi-directional causalities is greater during the crisis than in the pre-crisis period, because of financial contagion. Furthermore, the causality analysis shows that the direction of the Granger cause-effect for the pre-crisis and crisis periods is not invariant in the considered time-scales, and that the causality directions among the studied stock markets do not seem to have a preferential direction. These results are relevant to better understand the behaviour of vulnerable stock markets, especially for investors and policymakers.
\end{abstract}

Keywords: Non-stationary time series; nonlinear causality test; MODWT; PIIGS; rolling-window wavelet correlation.

\section{Introduction}

International stock markets have become the focus of increasing empirical research in recent years. Of particular interest has been the analysis of European stock markets [10, 22, 29, 70], with special attention to stock markets that belong to the European Monetary Union (EMU) [25, 27, 33, 70]. A better knowledge of these stock markets is of vital importance for investors, economists and policymakers, seeing that the economic crisis

${ }^{*}$ Corresponding Author: josue.polanco@bc3research.org/josue.m.polanco@gmail.com (J. M. Polanco-Martínez) 
recently experienced in the Eurozone in the period 2008-2011 has been recognized as one of the most serious ever reported [25]. For example, several studies have shown [5, 6, 74] that this financial crisis caused uneven effects on the informational efficiency of European corporate bond sectors, especially those related to financial services (banks, insurance, etc.). In contrast, some non-financial sectors (chemicals, automobiles, construction, etc.) suffered only a transitory efficiency loss [5, 6, 74]. This recent financial crisis provides a unprecedented opportunity to measure the performance of traditional risk estimators and the different impacts across international markets, such as the EMU stock markets. For instance, developed markets tend to be more stable, and traditional risk measures based on past behavior tend to underestimate risk when a systemic crisis occurs [64].

Since the financial sub-prime crisis (2007) and the Lehman Brothers bankruptcy (2008), five members of the EMU (the so-called PIIGS countries: Portugal, Italy, Ireland, Greece and Spain) have become the economies most affected by recent high public debt/deficit, low competitiveness and/or unemployment [71]. These EU peripheral economies, and their respective stock markets, are under intense scrutiny as doubts arise concerning their growth and stability, with important consequences for the future of the EMU. One of the key questions that emerges is how the stock markets of these countries have been interlinked prior to and during the financial crisis.

A vast number of studies investigating the correlation and relationships among European stock markets are based mainly on the estimation of a correlation matrix of returns, bivariate and multivariate cointegration theory, or by using generalized VAR or (G)ARCH models $[27,34,39,62]$. However, cointegration theory can only tackle short-run versus long-run time horizons and the VAR or $(\mathrm{G}) \mathrm{ARCH}$ approaches are sensitive to model specifications [41]. In contrast, from a practical point of view, we may point out that stock markets are not stationary and involve heterogeneous agents who make decisions across different time horizons and operate on different time scales (frequencies) [28, 31, 54].

A mathematical tool that can handle non-stationary time series and works in the combined time-and-scale domain is the Discrete Wavelet Transform (DWT) [31, 47]. There are different algorithms to compute the DWT. In this paper, we make use of the Maximal Overlap Discrete Wavelet Transform (MODWT) because of its advantages over the classical DWT [31, 47]. Over the past few years, some of the most used wavelet tools to study the relationship between non-stationary time series have been the wavelet correlation [28, 31, 41, 45, 51, 73], the wavelet multiple correlation [24] and, more recently, the rolling-window wavelet correlation $[1,9,16,53,65]$. The wavelet correlation is a very useful statistical tool to be used in bivariate analysis. However, it does not take into account the presence of "causality" between two time series, and in many studies, it is necessary to use a causality test in order to understand the direction of the causality (in case it exists) between two time series [18, 49].

The main objective of the present work is to analyse and compare the PIIGS stock markets, using the S\&P Europe 350 as a European benchmark market index, within two different time intervals. The first interval (2004:1:2-2007:12:31) is characterized by market growth and low volatility, while the second period (2008:1:2-2011:12:31) shows a high volatility due to the financial crisis (Fig. 1). In order to achieve this aim, we 
use the rolling-window wavelet correlation (RWWC) computed via the MODWT. Moreover, we propose to use a novel graphical tool to visualise the RWWC in a simpler and more efficient way than the classical use of the RWWC. In order to analyze the interelationships among the stock markets during the pre-crisis and crisis periods, we apply a non-parametric and non-linear causality test to the wavelet decompositions of the stock market returns. It is worth mentioning that this kind of causality test has not been widely explored to study stock markets indices, and in particular, peripheral EU stock markets.

The remainder of this article is organized as follows. Section 2 describes the data used and the employed methodologies. Section 3 presents the results and discussion. Finally, Section 4 concludes the paper.

\section{Materials and methods}

\subsection{Data}

The data employed in this study are composed of daily closing prices indices of PSI20 (Portugal), ISEQ (Ireland), MIB30 (Italy), ASE20 (Greece), IBEX35 (Spain) and SPEURO (S\&P Europe 350; used as an EU stock market benchmark). All data sets encompass the interval from January 2, 2004 to December 31, 2011. However, the analysis is performed in two sub-intervals: the first (pre-crisis period) from January 2, 2004 to December 31, 2007 (1042 datapoints), and the second (crisis period) from January 2, 2008 to December 31, 2011 (1044 datapoints). The number of datapoints in each interval is practically the same to improve comparability. In order to cope with the different official holidays, we have adjusted the indices using the last closing price corresponding to each official holiday. Data were obtained from Yahoo, ${ }^{1}$ except for the PSI20 and SPEURO stock market indices, which were taken from BolsaPT ${ }^{2}$ and OnVista Group, ${ }^{3}$ respectively.

The analysis was conducted using daily returns, that is, $R_{t}=\log \left(S_{t} / S_{t-1}\right)=\Delta \log S_{t}$, where $S_{t}$ are the adjusted stock market indices at time $t$. Figure 1 shows the daily log returns $R_{t}$, in which we can easily identify an increase of volatility after the first half of 2008 .

\subsection{Wavelet decomposition}

Discrete Wavelet Transform (DWT) is a time series analysis technique that can handle non-stationarity by working in the combined time-and-scale domain $[31,47]$. One of the most common algorithms for computing the DWT is the Maximal Overlap Discrete Wavelet Transform (MODWT) because of its advantages over the classical DWT [47]. Firstly, the MODWT can handle samples of any size $N$, while the DWT restricts the sample size to a multiple of $2^{J}$, where $J$ is the level of the decomposition. More

\footnotetext{
${ }^{1}$ https://finance.yahoo.com/world-indices

${ }^{2}$ http: //www. bolsapt.com/historico/PSI20.NX/

${ }^{3}$ http://www . onvista.de/index/S-P-EUROPE-350-Index-8404704
} 
importantly, the MODWT is invariant to circular shifting of the time series under analysis, while the DWT is not. Furthermore, while both the DWT and MODWT can be used for an analysis of variance based on wavelet and scaling coefficients, the MODWT wavelet variance estimator can be shown to be asymptotically more efficient than the same estimator based on DWT [31, 46, 47, 49, 50].

We decomposed ${ }^{4}$ the daily log returns $R_{t}$ for the two time intervals (pre-crisis and crisis periods) applying the MODWT with a Daubechies least asymmetric (LA) wavelet filter of length $L=8$, commonly denoted as $L A(8)[17,31]$. The maximum decomposition level $J$ is given by $\log _{2}(N)[31,47]$, which in this case translated into a maximum level of 10 (the number of datapoints for the pre/crisis period are close to 1040). Since the number of feasible wavelet coefficients becomes critically small for high levels, and to avoid boundary coefficients, we chose the wavelet analysis with $J=7$, so that the MODWT produced seven wavelet coefficients and one scaling coefficient, that is, $\widetilde{w}_{1, t}, \ldots, \widetilde{w}_{7, t}$ and $\widetilde{v}_{7, t}$, respectively. It is also noted that for the rolling-window wavelet correlation (RWWC) $J$ is equal to four (it is technically possible to estimate the RWWC up to the level five, but the correlation values on this upper level show such a high variability that does not provide any useful information; cf. Sect. 2.4). This is due to the length of the rolling-window (250 days), which causes a reduction in the maximum level.

The level of the transform defines the scale of the respective wavelet coefficients $\widetilde{w}_{t, j}$. In our particular case, for all families of Daubechies compactly supported wavelets, the level $j$ wavelet coefficients are associated with changes at the effective scale $\lambda_{j}=2^{j-1}$ days [28]. Moreover, the MODWT utilizes approximately ideal bandpass filters within the frequency interval $\left[1 / 2^{j+1}, 1 / 2^{j}\right)$ for scale levels $1 \leq j \leq J$. Inverting this frequency range and multiplying it by the appropriate time unit $\Delta t$ (one day, in our case), we have the equivalent periods of $\left(2^{j}, 2^{j+1}\right] \Delta t$ days for scale levels $1 \leq j \leq J$ [69]. This means that in our case study, with daily data, the scales $\lambda_{j}$ of the wavelet coefficients (with $j=1, \ldots, 7$, viz. time horizons associated with changes of $1,2,4,8,16,32$, and 64 days) are associated to day periods of, respectively, 2-4 (includes most intraweek scales), 4-8 (including the weekly scale), 8-16 (fortnightly scale), 16-32 (monthly scale), 32-64 (monthly to quarterly scale), 64-128 (quarterly to biannual scale) and 128-256 (biannual scale) $[28,49]$.

\subsection{Wavelet correlation}

In order to analyse the relationships among the five daily log returns of the PIIGS countries at different time horizons and periods, we have computed the MODWT wavelet correlation (WC). We followed the methodology to compute the MODWT and WC proposed by Gencay et. al. [31], as implemented in the R packages Waveslim [67] and W2CWM2C [50]. The MODWT unbiased estimator of the wavelet correlation for scale $\lambda_{j}$ between two times series $X$ and $Y$ can be expressed as follows [31]

85 86 87 88 89 90 91 92 93 94 95 96 97 98 99 100 101 102 103 104 105 106 107 108 109 110 111 112 113 114 115

${ }^{4}$ All the MODWT decompositions are available from the Corresponding Author upon request. 


$$
\widetilde{\rho}_{X Y}=\frac{\operatorname{cov}\left(\widetilde{W}_{X, j, t}, \widetilde{W}_{Y, j, t}\right)}{\sqrt{\operatorname{var}\left\{\widetilde{W}_{X, j, t}\right\} \operatorname{var}\left\{\widetilde{W}_{Y, j, t}\right\}}}=\frac{\widetilde{\gamma}_{X Y}\left(\lambda_{j}\right)}{\widetilde{\sigma}_{X}\left(\lambda_{j}\right) \widetilde{\sigma}_{Y}\left(\lambda_{j}\right)}
$$

where $\widetilde{\gamma}_{X Y}\left(\lambda_{j}\right)$ is the unbiased estimator of the wavelet covariance between wavelet coef- ${ }^{123}$ ficients $\widetilde{W}_{X, j, t}$ and $\widetilde{W}_{Y, j, t}$, while $\widetilde{\sigma}_{X}^{2}\left(\lambda_{j}\right) \widetilde{\sigma}_{Y}^{2}\left(\lambda_{j}\right)$ are the unbiased estimators of the wavelet ${ }_{124}$ variances for $X$ and $Y$ respectively, associated with scale $\lambda_{j}$. The unbiased estimator of ${ }_{125}$ the wavelet variance based on the MODWT is defined [31] by

$$
\widetilde{\sigma}_{X}^{2}\left(\lambda_{j}\right)=\frac{1}{\widetilde{N}_{j}} \sum_{t=L_{j}-1}^{N-1} \widetilde{W}_{j, t}^{2}
$$

where $\left\{\widetilde{W}_{j, t}\right\}$ are the $j$ th level MODWT wavelet coefficients for the time series $X, L_{j}={ }_{127}$ $\left(2^{j}-1\right)(L-1)+1$ is the length of scale $\lambda_{j}$ wavelet filter, and $\widetilde{N}_{j}=N-L_{j}+1$ is the ${ }^{128}$ number of the coefficients not affected by the boundary. ${ }_{129}$

The confidence interval $100(1-2 p) \%$ for the $\mathrm{WC}$ is based on the extension proposed by ${ }_{130}$ Witcher et al. [68] of the classical result on the Fisher Z-transformation of the correlation ${ }_{131}$ coefficient [69]. Thus, an approximate $100(1-2 p) \%$ confidence interval for the $\mathrm{WC}$ is given ${ }_{132}$ by $\tanh \left\{h\left[\widetilde{\rho}_{X Y}\left(\lambda_{j}\right)\right] \pm \phi^{-1}(1-p) / \sqrt{\widetilde{N}_{j}-3}\right\}$, where $\phi^{-1}(p)$ is the $100 p \%$ percentage point ${ }^{133}$ for the standard normal distribution, and the function $h\left(\widetilde{\rho}_{X Y}\right)=\tanh ^{-1}\left(\widetilde{\rho}_{X Y}\right)$ defines the ${ }_{134}$ Fisher Z-transformation [31, 69].

\subsection{Rolling-window wavelet correlation}

To analyze the temporal variation of the wavelet correlation(WC), a dynamic measure is needed. For this reason, we calculated the rolling-window wavelet correlation (RWWC), that is, wavelet correlations computed in moving windows. Since the introduction of the RWWC in economic studies by Ranta [52], this technique has been used in several economical/financial studies $[9,16]$. One of the advantages of the RWWC is its ability to analyze distinct time intervals (for instance, in our case, the pre-crisis and crisis periods). We have followed the methodology implemented by Benhmad [9], Dajcman et al. [16] and Ranta [52]. We have computed the pairwise rolling-window wavelet correlation with windows $w=250$ datapoints (one trading year), rolling forward one datapoint at a time, and centered around the time $t$ as in Dajcman et al. [16] and Benhmad [9]. For this reason, the effective number of wavelet scales is in principle limited to five $(J=5)$. However, we have decided to analyze only the first four wavelet scales because, after applying the MODWT to a sub-sample (or "window") with 250 datapoints and trying to avoid the boundary wavelet coefficients, the number of datapoints is much smaller than 250 for scale D5. Thus, we have obtained $N-w$ (where $\mathrm{N}=1043$ and w $=250$, then, $N-w$ $=793$ ) windows, and therefore, correlation coefficients. Finally, we have introduced a new way of visualizing the RWWC. The code is available from the Corresponding Author upon request, and it will also be available in the next version of our $\mathrm{R}$ package W2CWM2C freely available from CRAN repository [50]. 


\subsection{Nonlinear Causality Test}

The linear Granger causality test is a statistical tool frequently used to investigate potential "causal" relationships among different kinds of time series. However, this tool does not take into account "potential" nonlinear causal relationships among time series. For instance, it is well known that financial and commodity markets are dynamical systems that may manifest nonlinearities (e.g., structural breaks, regime shifts, extreme volatility, among others), especially when the data sets are relatively large [60]. In order to address the non-linear Granger causality in the bivariate analysis, many non-linear tests have been developed. For instance, Baek and Brock [4] proposed a nonparametric test for detecting nonlinear causal relationships. Later, Hiemstra and Jones [35] provided an improved version of Baek and Brock [4]. The test of Hiemstra and Jones [35] is one of the most used nonlinear causality tests in economics and finance ${ }^{5}$. However, it tends to over-reject the null hypothesis when the test is satisfied [19, 20]. For this reason, Diks and Panchenko [20] proposed a new nonparametric and nonlinear Granger causality test to avoid the over-rejection. In this work, we use this later causality test applied to the two time intervals of study (pre-crisis and crisis periods), as implemented in the $\mathrm{C}$ program GCTtest, which is freely available online ${ }^{6}$. The description of the test is presented in the following lines, and it is based on Diks and Panchenko [20] and Bekiros and Diks [7].

Testing Granger causality between two time series $\mathbf{X}_{t}$ and $\mathbf{Y}_{t}$ is based on the null hypothesis that $\mathbf{X}_{t}$ does not contain additional information about $\mathbf{Y}_{t+1}[7,20]$. Now, assuming as delay vectors $\mathbf{X}_{t}^{l_{X}}=\left(X_{t-l_{X}+1, \ldots, X_{t}}\right)$ and $\mathbf{Y}_{t}^{l_{Y}}=\left(Y_{t-l_{Y}+1, \ldots, Y_{t}}\right)$, where $l_{X}, l_{Y} \geq 1$ denote the delays for $\mathbf{X}_{t}$ and $\mathbf{Y}_{t}$, respectively, the null hypothesis can be defined [7] as

$$
H_{o}: \mathbf{Y}_{t+1}\left|\left(\mathbf{X}_{t}^{l_{\mathrm{X}}} ; \mathbf{Y}_{t}^{l_{\mathrm{Y}}}\right) \sim \mathbf{Y}_{t+1}\right| \mathbf{Y}_{t}^{l_{\mathrm{Y}}}
$$

By assuming $\mathbf{Z}_{t}=\mathbf{Y}_{t+1}$ and dropping times indices in (3), the conditional distribution 178 of $Z$ given $(X, Y)=(x, y)$ is the same as that of $Z$ given $Y=y$ under the null hypothesis $\quad 179$ $[7,20]$. The null hypothesis (3) can be expressed in terms of joint distributions that the ${ }_{180}$ joint probability density function $f_{X, Y, Z}(x, y, z)$ and its marginals satisfy the relationship ${ }_{181}$

$$
\frac{f_{X, Y, Z}(x, y, z)}{f_{Y}(y)}=\frac{f_{X, Y}(x, y)}{f_{Y}(y)} \frac{f_{Y, Z}(y, z)}{f_{Y}(y)}
$$

This explicitly states that $X$ and $Z$ are conditionally independent of $Y=y$ for each ${ }_{182}$ fixed value of $y[7,20]$. Diks and Panchenko [20] demonstrated that the null hypothesis ${ }_{183}$ (3) can be expressed as

$$
q \equiv \mathbb{E}\left[f_{X, Y, Z}(X, Y, Z) f_{Y}(Y)-f_{X, Y}(X, Y) f_{Y, Z}(Y, Z)\right]=0
$$

\footnotetext{
${ }^{5}$ In the literature there are several nonlinear causality tests (e.g. Bell et al. [8], Su and White [61], Dionision et al. [21]; among others), but these are less frequently used.

${ }^{6}$ http://research.economics.unsw.edu.au/vpanchenko/software/2006_GC_JEDC_c_and_exe_ code.zip
} 
where $\mathbb{E}$ denotes the expectation operator. An estimator for $q$ according to Diks and ${ }_{185}$ Panchenko [20] is

$$
T_{n}\left(\epsilon_{n}\right)=\frac{(2 \epsilon)^{-d_{X}-2 d_{Y}-d_{Z}}}{n(n-1)(n-2)} \sum_{i}\left[\sum_{k, k \neq i} \sum_{j, j \neq i}\left(\boldsymbol{I}_{i k}^{X Y Z} \boldsymbol{I}_{i j}^{Y}-\boldsymbol{I}_{i k}^{X Y} \boldsymbol{I}_{i j}^{Y Z}\right)\right]
$$

where $\boldsymbol{I}_{i j}^{W}=\boldsymbol{I}\left(\left\|W_{i}-W_{j}\right\|<\epsilon\right)$ ( $\boldsymbol{I}$ is the indicator or characteristic function $), W_{i} \quad{ }_{187}$ and $W_{j}$ are elements of a $d_{W}$-variate random vector $W, \epsilon$ is the bandwidth, and $n$ is the ${ }_{188}$ sample size $[7,20]$. Taking into account that the local density estimators of a $d_{W}$-variate ${ }_{189}$ random vector $W$ can be described as $\hat{f}_{W}\left(W_{i}\right)=(2 \epsilon)^{-d_{W}}(n-1)^{-1} \sum_{j, j \neq i} \boldsymbol{I}_{i j}^{W}$, then the 190 T-statistics according to Diks and Panchenko [20] can be defined as

$$
T_{n}\left(\epsilon_{n}\right)=\frac{(n-1)}{n(n-2)} \sum_{i}\left[\hat{f}_{X, Y, Z}\left(X_{i}, Y_{i}, Z_{i}\right) \hat{f}_{Y}\left(Y_{i}\right)-\hat{f}_{X, Y}\left(X_{i}, Y_{i}\right) \hat{f}_{Y, Z}\left(Y_{i}, Z_{i}\right)\right]
$$

For the case $\epsilon_{n}=C n^{-\beta}$, with $\beta \in(1 / 4,1 / 3)$ and $C>0$, and for the lag- $1 l_{X}=l_{Y}=1, \quad{ }_{192}$ the T-statistics (7) is asymptotically normally distributed and satisfies

$$
\sqrt{n} \frac{\left(T_{n}\left(\epsilon_{n}\right)-q\right)}{S_{n}} \stackrel{\mathrm{d}}{\rightarrow} N(0,1)
$$

where $\stackrel{\mathrm{d}}{\rightarrow}$ indicates convergence in distribution and $S_{n}$ is an estimator of the asymptotic $\quad 194$ variance of $T_{n}[7,20]$.

\section{Results and discussion}

\subsection{Descriptive statistics and Pearson's correlation.}

Basic descriptive statistics of daily log returns $R_{t}$ are presented in Table 1 . The ${ }_{198}$ mean and median values have practically the same values (around zero) for the pre-crisis 199 and crisis periods for all daily log returns. The maximum/minimum values for the crisis 200 period are between two and three times greater/smaller than for the pre-crisis. On the ${ }_{201}$ other hand, the standard deviation, which is a simple measure of volatility, is practically 202 twice as large for the crisis period than for the pre-crisis period. The skewness (a measure 203 of asymmetry or more precisely the lack of symmetry) shows that for all cases the $R_{t}{ }^{204}$ has an asymmetric probability distribution. Additionally, the kurtosis values show that 205 none of them have a value close to 3 (the theoretical value for a Gaussian probability 206 distribution) indicating that none of the probability distributions of these time series 207 appears to be normally distributed. In order to confirm this finding, we performed the 208 Jarque-Bera test of the null hypothesis that the respective probability distribution of $R_{t} \quad{ }_{209}$ were Gaussian (chi-square with $d f=2$ ). The reported $p$-values led to the rejection of ${ }_{210}$ the null hypothesis in all cases. We notice that this lack of normality for $R_{t}$ is consistent ${ }_{211}$ 
with the well-known "stylized facts" of the market returns, as pointed out in previous 212 studies $[15,43]$.

Table 2 presents the correlation matrix, obtained by means of the Pearson's correla- ${ }^{214}$ tion coefficients, among the six daily stock market log returns analysed. The maximum ${ }_{215}$ correlations for the pre-crisis period take place for the pairs MIB30-SPEURO, IBEX35- ${ }_{216}$ SPEURO and MIB30-IBEX35, whereas for the crisis period occur for the pairs MIB30- ${ }_{217}$ IBEX35, MIB30-SPEURO and PSI20-IBEX35. The minimum correlations occur in the 218 pairs PSI20-ASE20 for the pre-crisis period and ASE20-SPEURO (but closely followed ${ }_{219}$ by ISEQ-ASE20) for the crisis period. This indicates to some extent that the PIIGS 220 members are more correlated among themselves than with one of the main European 221 stock market benchmarks [Notice that the S\&P Europe 350 index is dominated by the ${ }_{222}$ behaviors of the four greatest European markets, viz. the UK, France, Germany, and 223 Switzerland, which together comprise $73 \%$ of the index (viz. $28 \%$ from the UK and 224 roughly $15 \%$ from each of the other three $\left.\left.\operatorname{countries}^{7}\right)\right]$.

Following the same line of argument, the correlations for the crisis period between PIIGS members and SPEURO are not greatest than for the pre-crisis period (except PSI20-SPEURO). Indeed, the correlation decrease slightly for the pairs MIB30-SPEURO and IBEX35-SPEURO although the correlation remain practically the same for ISEQ- ${ }_{22}^{29}$ SPEURO and ASE20-SPEURO. This implies that the PIIGS stock markets do not seem 230 to show a direct transmission of information through the European market during the ${ }_{231}$ crisis period, at least when the PIIGS are compared with the S\&P Europe 350 index. 232 However, the Pearson's correlation is a global measure and it is not able to provide ${ }_{233}$ detailed information on this matter. For this reason, a deeper analysis is presented in 234 section 3.2 .

The strong correlation in MIB30-IBEX35, as well as the weak correlations in ASE20- 236 ISEQ and ASE20-PSI20, are all well-known results [23, 65], and will therefore not be ${ }_{237}$ further considered here. Undoubtedly, the most evident result in Table 2 is that the cor- 238 relation in the crisis period is greater than during the pre-crisis period for all the pairwise 239 correlation coefficients for PIIGS members. However, the increase in the correlation for 240 the crisis period is much more noticeable for the pairs PSI20-MIB30, PSI20-ASE20 and 241 PSI20-IBEX35, clearly indicating that the stock market index from Portugal is markedly ${ }_{242}$ present. This result is in accordance with other PIIGS stock markets analyses, some of 243 which are relatively close to the time intervals used in our study [32, 36, 37]. 244

Classical correlation analysis is a useful starting point to examine the correlation ${ }_{245}$ among market returns. However, this statistical technique provides a global measure of 246 the correlation between two time series in the time domain and co-movements among 247 market returns vary in time and also at different scales (frequencies or periods) [48, 55]. 248 Moreover, Livan et al. [42] have shown that the use of the standard Pearson estimator ${ }_{249}$ to compute correlation coefficients between financial markets in the presence of non- 250 stationary behaviour can be problematic. Therefore, it is necessary to use a statistical 251

\footnotetext{
${ }^{7}$ Standard \& Poor's 350 Europe Factsheet as of 31 May 2017. http://eu.spindices.com/indices/ equity/sp-europe-350
} 
tool, such as wavelet analysis, that can handle non-stationary time series and is able to 252 work in the combined time-and-scale domain $[28,31,54]$. An adequate tool to face these 253 drawbacks is the rolling-window wavelet correlation (RWWC) $[9,16,53,65]$. 254

\subsection{Dynamic correlation in the time-frequency domain}

Our RWWC analysis (Figure 2) shows that the rolling window wavelet correlations are, 256 in general, greater than zero, with coefficient values that range from -0.31 to 0.95 , but also 257 reveals some interesting details that cannot be obtained with the correlation matrix. For ${ }_{258}$ example, the co-movements between the stock market returns under study are time-scale 259 (frequency) dependent and the degree of correlation is not constant in time. This suggests 260 that correlation dynamics among the PIIGS stock markets consist of interactions between ${ }_{261}$ heterogeneous investors with different time horizons of trading. This corroborates some ${ }_{262}$ previous studies where the RWMC is used for other stock markets $[9,16]$. The correlation ${ }_{263}$ coefficients for the four wavelet scales, that is, from D1 to D4, imply time horizons ${ }_{264}$ associated with changes of 1 to 8 days and intraweek to monthly periods. This implies that ${ }_{265}$ the first two/three wavelet scales are more related with volatility events, whereas upper 266 scales like D4 represent processes that take place at lower frequencies, such as fundamental ${ }_{267}$ macroeconomic factors (trade, monetary policy, common shocks, etc.) [9, 12, 26, 29]. ${ }_{268}$

We found maximum correlations for the pairs MIB30-SPEURO, IBEX35-SPEURO ${ }_{269}$ and MIB30-IBEX35, followed to lesser extend by PSI20-MIB30 and PSI20-IBEX35, 270 while the minimum correlations take place for ASE20-SPEURO, ISEQ-ASE20, ASE20- ${ }_{271}$ IBEX35 and MIB30-ASE20 (Figure 2). These results confirm our findings obtained by ${ }_{272}$ means of the correlation matrix (Table 2). On the other hand, the RWWC reveals a very ${ }_{273}$ interesting finding: correlations during the crisis period for the pairs MIB30-SPEURO ${ }_{274}$ and IBEX35-SPEURO are less stronger than for the pair MIB30-IBEX35. This is more ${ }_{275}$ evident for the shortest wavelet scales D1 and D2 and for some particular time intervals, 276 like the period between SPC and DJS or the first quartile of 2011. Furthermore, for the 277 rest of the PIIGS stock market returns, the strongest correlations occur with the stock 278 market from Portugal, in particular for the pairs PSI20-IBEX30 and PSI20-MIB30. One 279 exception is the stock market from Ireland, which shows the strongest correlation with 280 SPEURO during all the time interval of study, and especially during the crisis period. ${ }_{281}$ This result suggests that the stock market indices from Portugal, Italy and Spain were ${ }_{282}$ more interconnected among themselves during the crisis than with the European market ${ }_{283}$ benchmark.

The strong correlation between ISEQ and SPEURO is a simple consequence of the fact that the UK is not only the main economic partner of Ireland [13, 38], but also the major influence on the SPEURO index, with a weight of $28 \%$ (cf. Footnote 7 ). On the other hand, it is somewhat surprising to observe the low correlation at shorter time scales (D1-D3) between ASE20 and MIB30, as well as between ASE20 and SPEURO, seeing that Italy and Germany are Greece's top trading partners. This can be mainly explained by two reasons. First, stock market indices are not only composed by financial services companies (banks, insurance, etc.) but also by others kind of companies (industry, construction, services, etc). However, the 2008 financial crisis affected notably the financial

284
285
286
287
288
289
290
291
292
293


sector (banks, insurance, etc.) $[5,6,58,74]$. Second, ASE20 as an economical indicator ${ }^{294}$ of a country with serious economical problems, which produces a very volatile index. In 295 any case, what can be clearly seen is the increased medium-term (D4) correlation after ${ }_{296}$ each major crisis event (in particular after the subprime crisis, the Lehmann-Brothers col- ${ }_{297}$ lapse, and the sovereign debt crisis). Furthermore, our findings show that for all pairwise 298 comparisons with respect to Greece and during the pre-crisis interval, the correlations 299 show values with an ascending trend (Figure 2). On the contrary, for the crisis period, 300 the correlations tend to decrease (except for the pair PSI20-ASE20 that does not show 301 a clear trend). This decreasing trend is much more marked for ASE20-SPEURO and 302 in a lower degree for MIB30-ASE20 and ASE20-IBEX35. This means that ASE20, and 303 despite the high correlation during the crisis with respect to the pre-crisis period, tends 304 to move away from the European benchmark market since the 2008 financial crisis till at 305 least to the end of 2011.

Across practically all wavelet scales and in almost every pairwise comparison, we 307 observe higher correlations during the crisis period than during the pre-crisis period 308 (Figure 2). It should be pointed out, however, that the most remarkable result in our 309 RWWC analysis is that in many cases the strongest correlations coincide with the main 310 financial turmoil events during the crisis period, such as, the subprime crisis (SPC), 311 and in particular manner during the Lehman-Brothers collapse (LBC) and the Greece's 312 sovereign debt crisis (SDC). As is well known, an increase in correlation during financial 313 crisis has been reported in other works where PIIGS stock markets indices have been 314 used $[23,65]$ and for others stock market indices from several regions around the world 315 $[9,16,59,66]$.

\subsection{Nonlinear multiscale causality}

In order to gain more insight into the interrelations between pairs of all daily stock market log returns under scrutiny in the time-scale domain, we present and discuss the results obtained with the nonlinear causality test applied to wavelet decomposition coefficients of these returns (Figure 3 and Tables 3 and A.2). However, before discussing the multi-scale and bivariate causality test results, it is important to take into account the following two points: 1) a uni-directional causality indicates that changes in one stock market can cause changes in another one; 2) a bi-directional (or simultaneous) causality ${ }^{8}$ indicates that changes in one stock market can affect a second one, but changes in this second market can also affect the first one. Bi-directional causality indicates a high degree of interaction between two markets. From a financial point of view, the existence of causality in two stock markets implies that, to some extent, one market might sometimes be used to forecast the other. This means that this information should be taken into account in the portfolio diversification strategy.

The most relevant result from our multi-scale causality test is that the number of unidirectional and bi-directional causalities is greater during the crisis than in the pre-crisis period (41 versus 22 statistically significant causal relationships) in the first three wavelet

\footnotetext{
${ }^{8}$ It is also relatively common to use the term "feedback" to refer to a bidirectional causality.
} 
scales (Table 3). There are several studies that have established that different financial 334 markets tend to be more closely linked during financial crisis, with contagion ${ }^{9}$ being the 335 main mechanism to explain this phenomenon $[30,36,57,72]$. The transmission of shocks 336 due to contagion in financial markets is very fast and can take place within a few days, 337 tending to vanish with five days or less $[3,29]$. On the other hand, the first wavelet 338 scales D1, D2 and D3 are associated to changes of 1, 2 and 4 days. For this reason, it 339 is feasible that contagion could explain our strong cross-country causation in the highest 340 frequencies.

This contagion during the crisis period could be due to transmission among PIIGS stock markets or it can be introduced by "external factors", for example, instabilities contained in other European or even more overseas stock markets, such as the burst of the subprime bubble at the end of July 2007 in the USA, although a corroboration of this last hypothesis is beyond the aim of our paper. However, our non-linear bi-variate causality analysis applied for the crisis period (Table 3 and Figure 3) reveals that when the stock market from Greece is implicated, the total number of relationships statistically significant that leads the other markets is zero, but this number is maximum when ASE20 is a follower (indeed the stock markets that show the highest number of leads among the six markets analysed, come from Italy and Spain, with 5 and 4 relationships, respectively). On the other hand, there is only one bidirectional causality (ASE20-SPEURO for scale D2), which implies that there is not a direct transmission of information between ASE20 and the other markets analysed. Nevertheless, a volatile financial process, such as financial contagion, could be transmitted via a third PIIGS stock market. Figure 3 illustrates how the stock markets are interconnected among them. For the case of Greece, 356 it is easy to observe an increase in the number of interconnections for the crisis period 357 and for the first three scales, and especially for the last two ones.

This last intriguing result is in apparent contradiction to the expectation that Greece would transmit its high volatility to other PIIGS stock markets during the crisis period, since it is one of the EMU members most affected by the sovereign debt $[14,36,40$, 56]. However, there are some studies in the same line with our results. For example, Bhanot et al. [11] analysed the relationship between sovereign yields of PIIGS and other EMU members during the financial crisis (from $7 / 2007$ to 4/2011). Despite identifying a significant increase in the unconditional correlation between the yield spreads of Greece and the other EMU markets during the crisis, they found that the conditional correlation between yield spreads of Greece, the rest of PIIGS, and other EMU members decreased during the crisis, after accounting for time-varying volatility and changes in fundamental factors. This suggests that there was no contagion from Greece to PIIGS and other EMU countries. Bhanot et al. [11] finally concluded that news announcements and the banking channel were the main transmission pathways in the crisis period. Moreover, Tamakoshi and Hamori [63] pointed out that contagious linkages of equity markets, due

\footnotetext{
${ }^{9}$ Contagion can be defined, according to [26], as a "significant increase in cross-market linkages after a shock to one country or group of countries, and it is only contagion if cross-market co-movement increases significantly after a shock"; for example, a financial crisis.
} 
to the sovereign debt crisis from Greece to neighbouring countries, may have occurred at 373 the level of speculative bubble portions rather than among stock indices themselves. 374

Another plausible explanation for this result is that our time interval for the cri- 375 sis period could be too long and might reduce the effectiveness of the causality test. To 376 address this point we computed the nonlinear causality test for the time interval 10/2009- 377 10/2010, which covers one of the most turbulent stages during the Greece sovereign debt 378 crisis (SDC). However, the results obtained with this test (results not shown) are practi- 379 cally identical to the previous ones obtained for the interval 2008-2011 and presented in 380 Table 3. Therefore, we can rule out this possibility. 381

In addition to this, we would like to denote that the previous result related with 382 financial contagion, is in partial concordance with the findings of Samitas and Tsakos 383 (2013) who found contagion effect from Greece to other PIIGS members during the 2008384 financial crisis, but not during the SDC. On other hand, and as we have discussed earlier, 385 PIIGS stock markets are not isolated, so that contagion and other financial shocks could 386 come from external factors (including European or overseas stock markets) $[2,36,37,387$ 44, 72]. For example, recently Sandoval Jr. [58], based on a transfer entropy method 388 and a nonlinear generalization of Granger causality test, analysed the stocks of the 197389 largest financial companies (which are components of the S\&P 1200 Global index) in the 390 world. This work analysed which of those institutions were the most affected by the stock 391 markets of Portugal, Ireland, Italy, Greece, Spain and Cyprus. The main result found 392 was that stocks from Belgium, Denmark, France, Germany, Greece, the Netherlands, 393 Spain and UK were the most affected [58]. This result indicates that there is also a large 394 amount of transfer entropy between those countries and the PIIGS. Therefore, this result 395 should be taken into consideration or at least to be aware of it when a subset of European 396 stock markets are analysed.

A further analysis in the pairwise multi-scale bivariate causality test for the wavelet scales from D1 to D3 (Table 3) reveals that the pairs with the most statistically significant causalities are ISEQ-IBEX35 (with 6 out of 6) followed closely by the pairs PSI20 MIB30, PSI20-ISEQ, PSI20-IBEX35, MIB30-ISEQ, PT-SPEURO, IT-SPEURO and IE-SPEURO (with 5 out of 6 ). Before the crisis ISEQ leads IBEX35 (Scale D1) or vice versa (Scale D3) and there does not seem to be a preferential causality direction, whereas after the crisis there is a bidirectional causality on the three scales. As we have discussed earlier, volatile financial process (e.g., contagion) could be transmitted via a third PIIGS stock market. For instance, for the case of ISEQ-IBEX35, it is easy to appreciate (Figure 3) that ISEQ and PSI20 are ever connected with the European market benchmark (SPEURO) showing a bidirectional causality all the time for the first three wavelet scales, which supports the hypothesis of an indirect influence. This market could be PSI20 or ISEQ, but PSI20 shows a bidirectional causality with ISEQ and IBEX35 in the three scales, guaranteeing a interactive flow of information. Thus, it is highly probable that the "third market" belongs to Portugal. The strong interrelation during the crisis between IBEX35 and PSI20 can be explained due to the fact that Spain and Portugal are neighbouring countries and both maintain a strong commercial exchange. Thus, the existence of instabilities (including financial contagion) in any of these markets 
could amplify more easily the effects between them. Furthermore, PSI20 is almost always present in the second group of pairs with more causalities, indicating that PSI20 is the most sensitive and therefore most vulnerable PIIGS member. These results are similar to those obtained by other authors $[14,36]$ where stock and CDS markets were analysed before and after the 2008 financial crisis. In contrast, PSI20-ASE20 is the pair that shows the smallest number of statistically significant causalities (2 out of 6 ). Indeed, PSI20-ASE20 is one of the pairs that show a weak correlation before (0.3393) and during (0.5949) the crisis (Table 2). It is therefore not surprising that we find for this pair a low number of causalities for the first three wavelet scales.

Finally, the analysis for the last three scales (D5, D6 and D7), which are related with the lower frequencies, shows that the number of uni-directional and bi-directional causalities for the pre-crisis and crisis periods are practically the same statistically significant causal relationships. Moreover, there are some pairs of markets that maintain their causality direction before and during the crisis, for example, MIB30-IBEX35 (D5-D7) and IBEX35-SPEURO (D5-D7); this is the only pair that never changes its causality directions before and during the crisis, ISEQ-ASE20 (D5 and D7), ISEQ-IBEX35 (D5), ASE20-IBEX35 (D6), PSI20-MIB30, PSI20-MIB30 (D7) and PSI20-ASE20 (D7). From the causality test it is straightforward to deduce that IBEX35 causes MIB30 in the scales D5 and D6 (time horizons associated with changes of 16 and 32 days and in the frequency domain from monthly to quarterly scales), but MIB30 causes IBEX35 in the scale D7 (time horizon associated with changes of 64 days and in the frequency domain it is related to a biannual scale). On the other hand, there are other pairs that change causality directions in at least two of these scales, e.g., MIB30-ASE20 (D5-D6) and PSI20-IBEX35 (D5-D7); the latter is the only pair that ever changes causality directions, which is not strange because PSI20 is the most sensitive and vulnerable PIIGS member. Moreover, there are some pairs where the causality is not statistically significant in at least one direction ${ }^{10}$. These results indicate that the direction of causality depends on the wavelet scale. In addition, the six markets analysed, at the higher scales D6 and D7 (long time horizons), show a clear evidence of high integration, especially once SPEURO is also considered, and where the PIIGS are led in the long run by overall European system (represented by SPEURO).

\section{Conclusions}

In this work we presented a statistical analysis of PIIGS and S\&P Europe 350 index ${ }_{448}$ (SPEURO) stock market indices over two characteristic periods. The first one, called ${ }_{449}$ the pre-crisis period (2004-2007), was characterized by market growth and low volatility, 450 while the second, called the crisis period (2008-2011), was distinguished by its high 451 volatility due to the global financial crisis.

To analyze the temporal variation of the wavelet correlation for the market returns, we ${ }_{453}$

\footnotetext{
${ }^{10}$ E.g., PSI20-ISEQ and PSI20-AS20 in D5 and D6, PSI20-MIB30 in D5, ISEQ-ASE20 in D6 and MIB30-ISEQ and ASE20-IBEX35 in D6 and D7
} 
used the rolling-window wavelet correlation (RWWC) with five wavelet scales, computed via the Maximal Overlap Discrete Wavelet Transform (MODWT). The first three wavelet scales (corresponding to time horizons of 1 to 8 days and intraweek to monthly periods) are more related with volatility events, whereas the fourth wavelet scale represents processes that take place at lower frequency, such as fundamental macroeconomic factors (trade, monetary policy, common shocks, etc.). This analysis revealed that the co-movements among PIIGS stock market returns are time-scale (frequency) dependent and the degree of correlation is not constant in time. This suggests that correlation dynamics among the PIIGS stock markets consists of interactions between heterogeneous investors with different time horizons of trading. The most relevant results obtained from the WMCC analyses are : 1) the correlation among the PIIGS stock market returns is stronger for the crisis than for the pre-crisis period and the strongest correlations coincide with the main financial turmoil events during the crisis period; 2) the stock market indices from Portugal, Italy and Spain were more interconnected among themselves during the crisis than with the European benchmark market; and 3) the stock market from Greece (despite the high correlation during the crisis with respect to the pre-crisis period) tends to move away from the European benchmark market since the 2008 financial crisis till at least to the end of 2011.

In order to analyze the interrelationships among the stock markets during the precrisis and crisis periods, we applied a non-parametric non-linear Granger causality test to the wavelet decompositions of the stock market returns. The test indicates that the number of uni-directional and bi-directional causalities is greater during the crisis than in the pre-crisis period, in the first three wavelet scales (intraweek, weekly and fortnightly) because of financial contagion. On the other hand, the causality analysis has shows that the direction of the Granger cause-effect for the pre-crisis and crisis periods is not invariant in the considered time-scales, and that the causality directions among the studied stock markets do not seem to have a preferential direction. However, the most remarkable results are the followings: 1) the contagion during the crisis period could be due to transmission among PIIGS stock markets or it can be introduced by "external factors", indicating that the PIIGS are not an isolated system; 2) the stock market from Portugal is the most sensitive and therefore most vulnerable PIIGS member; 3) the causality test at the higher scales (quarterly and biannual scale) shows a clear evidence of high integration, especially when SPEURO is also considered, and where PIIGS are led in the long run by overall European system (represented by SPEURO).

A better understanding of these stock markets is vital for investors, economists and policymakers, specially since the economic crisis recently experienced in the Eurozone has been recognized among the most serious ever reported. Thus, these results are relevant to better understand the behaviour of vulnerable stock markets.

\section{Acknowledgement}

J.M.P.M. was funded by a Basque Government post-doctoral fellowship. J.F.M. acknowledges financial support from UPV/EHU Econometrics Research Group (Basque Government Department of Education grant IT-642-13) and the Spanish Ministry of Economy, Industry 
and Competitiveness (grant TM2016-74931). M.B.N. (RYC-2013-13628) and S.H.F. (RYC- 496 2012-12167) acknowledge financial support from the Ramón y Cajal Research Fellowship of the ${ }_{497}$ Ministry of Economy and Competitiveness of Spain. We would like to show our gratitude to 498 the anonymous reviewers and the main Editor Prof. Stanley whose comments and suggestions 499 have been very helpful in improving this paper.

\section{References}

[1] C. T. Albulescu, D. Goyeau, and A. K. Tiwari. Contagion and dynamic correlation of 502 the main European stock index futures markets: a time-frequency approach. Procedia 503 Economics and Finance, 20:19-27, 2015.

[2] M. G. Arghyrou and A. Kontonikas. The EMU sovereign-debt crisis: Fundamentals, ex- 505 pectations and contagion. Journal of International Financial Markets, Institutions and 506 Money, 22(4):658-677, 2012.

[3] K.-H. Bae, G. A. Karolyi, and R. M. Stulz. A new approach to measuring financial 508 contagion. Review of Financial studies, 16(3):717-763, 2003.

[4] E. Baek and W. Brock. A general test for nonlinear Granger causality: Bivariate model. 510 Iowa State University and University of Wisconsin at Madison Working Paper, $1992 . \quad 511$

[5] A.F. Bariviera, M.B. Guercio, and L. B. Martinez. A comparative analysis of the infor- 512 mational efficiency of the fixed income market in seven european countries. Economics 513 Letters, 116(3):426-428, 2012.

[6] A.F. Bariviera, M.B. Guercio, and L.B. Martinez. Informational efficiency in distressed 515 markets: the case of european corporate bonds. The Economic and Social Review, 45(3, 516 Autumn):349-369, 2014.

[7] S. D. Bekiros and C.G. Diks. The relationship between crude oil spot and futures prices: 518 Cointegration, linear and nonlinear causality. Energy Economics, 30(5):2673-2685, $2008 . \quad 519$

[8] D. Bell, J. Kay, and J. Malley. A non-parametric approach to non-linear causality testing. $\quad 520$ Economics Letters, 51(1):7-18, 1996.

[9] F. Benhmad. Bull or bear markets: A wavelet dynamic correlation perspective. Economic 522 Modelling, 32:576-591, 2013.

[10] D.A. Bessler and J. Yang. The structure of interdependence in international stock markets. $\quad 524$ J. of International Money and Finance, 22(2):261-287, 2003.

[11] K. Bhanot, N. Burns, D. Hunter, and M. Williams. Was there contagion in Eurozone 526 sovereign bond markets during the Greek debt crisis. Working paper series No. 006FIN- 527 73-2012, The University of Texas at San Antonio, College of Business, USA., 2012.

[12] V. Bodart and B. Candelon. Evidence of interdependence and contagion using a frequency 529 domain framework. Emerging markets review, 10(2):140-150, 2009. 
[13] D. Bredin and S. Hyde. Regime change and the role of international markets on the stock 531 returns of small open economies. European Financial Management, 14(2):315-346, $2008 . \quad 532$

[14] A. S. Chouliaras, A. G. Christopoulos, D. Kenourgios, and P. Kalantonis. The PIIGS stock 533 markets before and after the 2008 financial crisis: a dynamic cointegration and causality 534 analysis. International Journal of Banking, Accounting and Finance, 4(3):232-249, $2012 . \quad 535$

[15] R. Cont. Empirical properties of asset returns: stylized facts and statistical issues. Quan- 536 titative Finance, 1(2):223-236, 2001.

[16] S. Dajcman, M. Festic, and A. Kavkler. European stock market comovement dynamics 538 during some major financial market turmoils in the period 1997 to 2010-a comparative 539 DCC-GARCH and wavelet correlation analysis. Applied Economics Letters, 19(13):1249- 540 1256, 2012.

[17] I. Daubechies. Ten lectures on wavelets. Society for Industrial Mathematics, 1992.

[18] G. Dewandaru, R. Masih, and A. M. M. Masih. What can wavelets unveil about the ${ }_{543}$ vulnerabilities of monetary integration? a tale of Eurozone stock markets. Economic 544 Modelling, 52:981-996, 2016.

[19] C. Diks and V. Panchenko. A note on the Hiemstra-Jones test for Granger non-causality. 546 Studies in Nonlinear Dynamics \& Econometrics, 9(2), 2005.

[20] C. Diks and V. Panchenko. A new statistic and practical guidelines for nonparametric ${ }_{548}$ Granger causality testing. Journal of Economic Dynamics and Control, 30(9):1647-1669, 549 2006.

[21] A. Dionisio, R. Menezes, and D. A. Mendes. Mutual information: a measure of dependency 551 for nonlinear time series. Physica A: Statistical Mechanics and its Applications, 344(1):326$329,2004$.

[22] A. Dionisio, R. Menezes, and D.A. Mendes. On the integrated behaviour of non- ${ }_{554}$ stationary volatility in stock markets. Physica A: Statistical Mechanics and its Applications, 555 382(1):58-65, 2007.

[23] F. Economou, A. Kostakis, and N. Philippas. Cross-country effects in herding behaviour: ${ }_{557}$ Evidence from four south European markets. Journal of International Financial Markets, 558 Institutions and Money, 21(3):443-460, 2011.

[24] J. Fernández-Macho. Wavelet multiple correlation and cross-correlation: A multiscale 560 analysis of Eurozone stock markets. Physica A: Statistical Mechanics and its Applications, 561 391(4):1097-1104, 2012.

[25] P. Ferreira, A. Dionísio, and G.F. Zebende. Why does the Euro fail? the DCCA approach. 563 Physica A: Statistical Mechanics and its Applications, 443:543-554, 2016.

[26] K. J. Forbes and R. Rigobon. No contagion, only interdependence: measuring stock market 565 comovements. The Journal of Finance, 57(5):2223-2261, 2002. 
[27] M. Fratzscher. Financial market integration in Europe: on the effects of EMU on stock 567 markets. International Journal of Finance \& Economics, 7(3):165-193, 2002.

[28] M. Gallegati. Wavelet analysis of stock returns and aggregate economic activity. Compu- 569 tational Statistics \& Data Analysis, 52(6):3061-3074, 2008.

[29] M. Gallegati. A wavelet-based approach to test for financial market contagion. Computa- 571 tional Statistics \& Data Analysis, 56(11):3491-3497, 2012.

[30] M. Gentile and L. Giordano. Financial contagion during the Lehman Brothers default 573 and sovereign debt crisis. Journal of Financial Management Markets and Institutions, 574 $1(2): 197-224,2013$.

[31] R. Gençay, F. Selçuk, and B. Whitcher. An Introduction to Wavelets and Other Filtering 576 Methods in Finance and Economics. Academic Press, 2002.

[32] R.Q. Han, W.J. Xie, X. Xiong, W. Zhang, and W.X. Zhou. Market correlation structure 578 changes around the great crash. Fluctuation and Noise Letters, 16(2):1750018, $2017 . \quad 579$

[33] G.A. Hardouvelis, D. Malliaropulos, and R. Priestley. EMU and European stock market 580 integration. The Journal of Business, 79(1):365-392, 2006.

[34] B. Harrison, R. Lupu, and I. Lupu. Statistical Properties of the CEE Stock Market Dy- ${ }^{582}$ namics. A Panel Data Analysis. Romanian Economic Journal, 13(37):41-54, 2010.

[35] C. Hiemstra and J. D. Jones. Testing for linear and nonlinear Granger causality in the 584 stock price-volume relation. The Journal of Finance, 49(5):1639-1664, 1994.

[36] A. Kalbaska and M. Gatkowski. Eurozone sovereign contagion: Evidence from the CDS 586 market (2005-2010). Journal of Economic Behavior \& Organization, 83(3):657-673, 2012. 587

[37] H. Kazemi and N. Sohrabji. Contagion in Europe: examining the PIIGS crisis. Interna- 588 tional Advances in Economic Research, 18(4):455-456, 2012.

[38] C. Kearney. The causes of volatility in a small, internationally integrated stock market: 590 Ireland, july 1975-june 1994. Journal of Financial Research, 21(1):85-104, 1998.

[39] S.J. Kim, F. Moshirian, and E. Wu. Dynamic stock market integration driven by the 592 European Monetary Union: An empirical analysis. J. of Banking \& Finance, 29(10):2475- ${ }^{593}$ $2502,2005$.

[40] R. Kizys and C. Pierdzioch. Contagious speculative bubbles: A note on the Greek sovereign 595 debt crisis. Economics Bulletin, 31(4):A296, 2011.

[41] H.S. Lee. International transmission of stock market movements: a wavelet analysis. $A p-{ }^{597}$ plied Economics Letters, 11(3):197-201, 2004.

[42] G. Livan, J. Inoue, and E. Scalas. On the non-stationarity of financial time series: impact 599 on optimal portfolio selection. Journal of Statistical Mechanics: Theory and Experiment, 600 2012(07):P07025, 2012. 
[43] R. N. Mantegna and H. E. Stanley. Introduction to Econophysics: correlations and Com- 602 plexity in Finance. Cambridge university press, 1999.

[44] S. Mollah, A.M.M. Shahiduzzaman Quoreshi, and G. Zafirov. Equity market contagion 604 during global financial and eurozone crises: Evidence from a dynamic correlation analysis. $\quad 605$ Journal of International Financial Markets, Institutions and Money, 41:151-167, 2016.

[45] J. Nikkinen, S. Pynnönen, M. Ranta, and S. Vähämaa. Cross-dynamics of exchange rate ex- 607 pectations: a wavelet analysis. International Journal of Finance 83 Economics, 16(3):205- 608 $217,2011$.

[46] D.B. Percival and H.O. Mofjeld. Analysis of Subtidal Coastal Sea Level Fluctuations Using 610 Wavelets. J. of the American Statistical Association, 92(439), 1997.

[47] D.B. Percival and A.T. Walden. Wavelet methods for time series analysis. Cambridge ${ }_{612}$ Univ $\operatorname{Pr}, 2006$.

[48] C. Pinho and M. Madaleno. Time frequency effects on market indices: world comovements. ${ }^{614}$ China-USA Business Review, 9(4):1-24, 2010.

[49] J. M. Polanco-Martínez and L.M. Abadie. Analyzing crude oil spot price dynamics versus long term future prices: A wavelet analysis approach. Energies, 9(12):1089, 2016.

[50] J. M. Polanco-Martínez and F. J. Fernández-Macho. Package W2CWM2C: Description, ${ }_{618}$ features, and applications. Computing in Science E Engineering, 16(6):68-78, 2014.

[51] J.B. Ramsey. The contribution of wavelets to the analysis of economic and financial data. $\quad 620$ Phil. Trans.: Math., Phys. and Eng. Sci., 357(1760):2593-2606, 1999.

[52] M. Ranta. Wavelet multiresolution analysis of financial time series. $\mathrm{PhD}$ thesis, University ${ }_{622}$ of Vaasa, Finland, Acta Wasaensia 223, Statistics 5, 2010.

[53] M. Ranta. Contagion among major world markets: a wavelet approach. International 624 Journal of Managerial Finance, 9(2):133-149, 2013.

[54] A. Razdan. Wavelet correlation coefficient of 'strongly correlated' time series. Physica A: ${ }_{626}$ Statistical Mechanics and its Applications, 333:335-342, 2004.

[55] A. Rua and L.C. Nunes. International comovement of stock market returns: A wavelet ${ }_{628}$ analysis. Journal of Empirical Finance, 16(4):632-639, 2009.

[56] A. Samitas and I. Tsakalos. How can a small country affect the european economy? the ${ }_{630}$ greek contagion phenomenon. Journal of International Financial Markets, Institutions and Money, 25:18-32, 2013.

[57] H. Sander and S. Kleimeier. Contagion and causality: an empirical investigation of four 633 Asian crisis episodes. Journal of International Financial Markets, Institutions and Money, 13(2):171-186, 2003. 
[58] L. Sandoval. Structure of a global network of financial companies based on transfer entropy. ${ }_{636}$ Entropy, 16(8):4443-4482, 2014.

[59] L. Sandoval and I. D. P. Franca. Correlation of financial markets in times of crisis. Physica ${ }_{638}$ A: Statistical Mechanics and its Applications, 391(1):187-208, 2012.

[60] R. Savit. When random is not random: An introduction to chaos in market prices. Journal 640 of Futures Markets, 8(3):271-290, 1988.

[61] L. Su and H. White. A nonparametric Hellinger metric test for conditional independence. Econometric Theory, 24(04):829-864, 2008.

[62] T. Syriopoulos. Dynamic linkages between emerging European and developed stock mar- ${ }_{644}$ kets: Has the EMU any impact? International Review of Financial Analysis, 16(1):41-60, 645 2007.

[63] G. Tamakoshi and S. Hamori. Transmission of stock prices amongst European countries ${ }_{647}$ before and during the Greek sovereign debt crisis. Economics Bulletin, 31(4):3339-3353, 2011.

[64] E.O. Thomasz and A.F. Bariviera. Risk behavior of stock markets before and after the subprime crisis. In Modeling and Simulation in Engineering, Economics, and Management, pages 83-90. Springer, 2013.

[65] A. K. Tiwari, M. I. Mutascu, and C. T. Albulescu. Continuous wavelet transform and rolling correlation of European stock markets. International Review of Economics 83 Finance, 42:237-256, 2016.

[66] G.-J. Wang, C. Xie, M. Lin, and H. E. Stanley. Stock market contagion during the global ${ }_{656}$ financial crisis: A multiscale approach. Finance Research Letters, 2017.

[67] B. Whitcher. waveslim: Basic wavelet routines for one-, two- and three-dimensional signal ${ }_{658}$ processing, 2013. $\mathrm{R}$ package version 1.7.3.

[68] B. Whitcher, P. Guttorp, and D.B. Percival. Mathematical background for wavelet estima- 660 tors of cross-covariance and cross-correlation. Technical Report Tech. Rep. 38, Natl. Res. ${ }_{661}$ Cent. for Stat. and the Environ, Seatle, 1999.

[69] B. Whitcher, P. Guttorp, and D.B. Percival. Wavelet analysis of covariance with application $\quad{ }_{663}$ to atmospheric time series. J. of Geophys. Res., 105(D11):941-962, 2000.

[70] J. Yang, I. Min, and Q. Li. European stock market integration: does EMU matter? J. of ${ }_{665}$ Business Finance \& Accounting, 30(9-10):1253-1276, 2003.

[71] H. Zemanek. Competitiveness Within the Euro Area: The Problem that still Needs to be ${ }_{667}$ Solved. Economic Affairs, 30(3):42-47, 2010.

[72] X. Zhang, B. Podobnik, D. Kenett, and H. E. Stanley. Systemic risk and causality dynamics of the world international shipping market. Physica A: Statistical Mechanics and its Applications, 415:43-53, 2017. 
[73] J. Zhou. Multiscale Analysis of International Linkages of REIT Returns and Volatilities. ${ }^{672}$ The Journal of Real Estate Finance and Economics, pages 1-26, 2011.

[74] L. Zunino, A.F. Bariviera, M. B. Guercio, L.B. Martinez, and O.A. Rosso. Monitoring the 674 informational efficiency of european corporate bond markets with dynamical permutation 675 min-entropy. Physica A: Statistical Mechanics and its Applications, 456:1-9, 2016. 


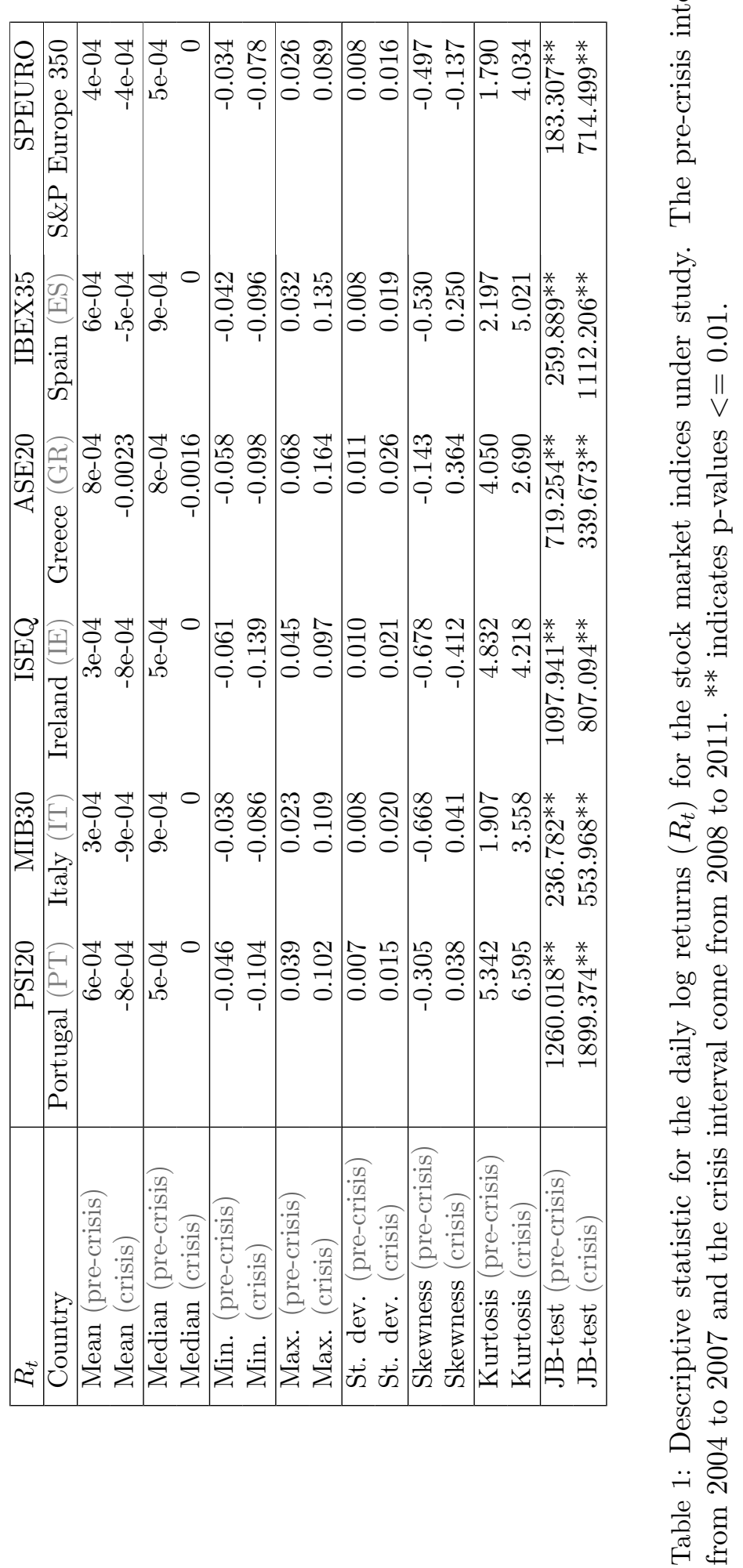




\begin{tabular}{|c|c|c|c|c|c|c|}
\hline$R_{t}$ & PSI20 & MIB30 & ISEQ & ASE20 & IBEX35 & SPEURO \\
\hline Country & Portugal (PT) & Italy (IT) & Ireland (IE) & Greece (GR) & Spain (ES) & S\&P Europe 350 \\
\hline \multicolumn{7}{|l|}{ Pre-crisis } \\
\hline PSI20 & 1 & & & & & \\
\hline MIB30 & $0.5153^{*}$ & 1 & & & & \\
\hline ISEQ & $0.4899 *$ & $0.6201 *$ & 1 & & & \\
\hline ASE20 & $0.3393^{*}$ & $0.4858^{*}$ & $0.4199 *$ & 1 & & \\
\hline IBEX35 & $0.5662^{*}$ & $0.8267^{*}$ & $0.6231^{*}$ & $0.4810^{*}$ & 1 & \\
\hline SPEUROEurope350 & $0.5566^{*}$ & $0.8700^{*}$ & $0.6924^{*}$ & $0.4911^{*}$ & $0.8545^{*}$ & 1 \\
\hline \multicolumn{7}{|c|}{\begin{tabular}{l|l} 
Crisis & \\
\end{tabular}} \\
\hline PSI20 & 1 & & & & & \\
\hline MIB30 & $0.7886^{*}$ & 1 & & & & \\
\hline ISEQ & $0.6305^{*}$ & $0.6918^{*}$ & 1 & & & \\
\hline ASE20 & $0.5949^{*}$ & $0.5653^{*}$ & $0.5105^{*}$ & 1 & & \\
\hline IBEX35 & $0.8060^{*}$ & $0.9012^{*}$ & $0.7050^{*}$ & $0.5726^{*}$ & 1 & \\
\hline SPEUROEurope350 & $0.6756^{*}$ & $0.8056^{*}$ & $0.6996^{*}$ & $0.4975^{*}$ & $0.7878^{*}$ & 1 \\
\hline
\end{tabular}

Table 2: Pairwise correlation matrix for daily $\log$ returns $\left(R_{t}\right)$ for the stock market indices under study. The pre-crisis interval come from 2004 to 2007 and crisis period come from 2008 to 2011. The symbol * indicates that the correlation values are statistically significant at $95 \%$ of confidence level. 


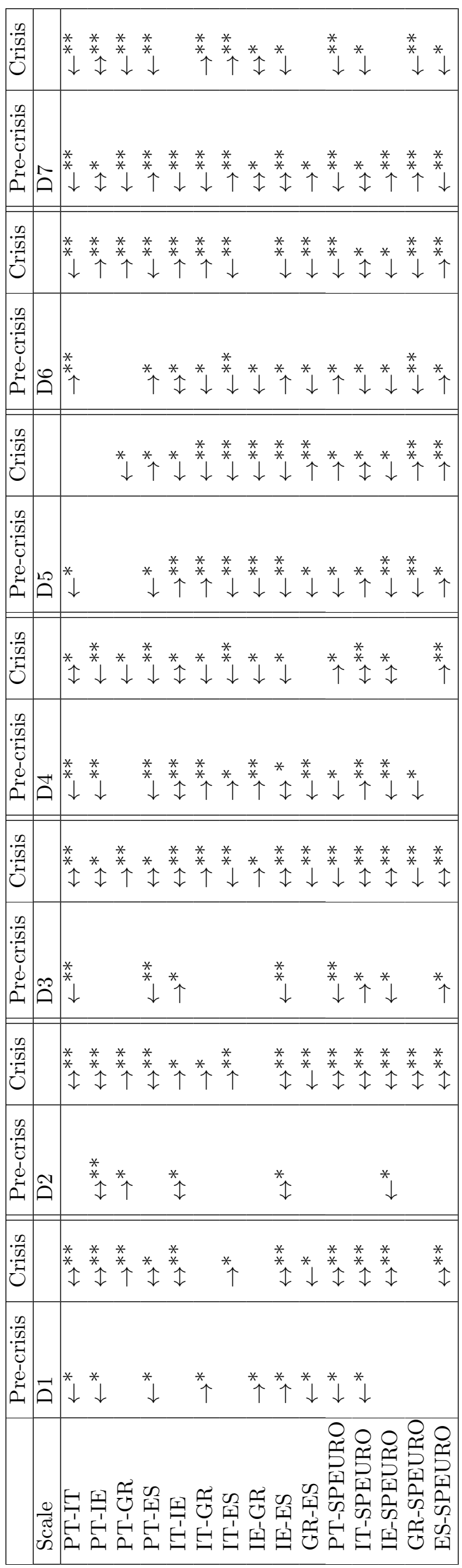

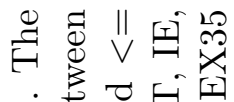

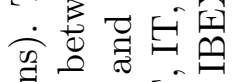

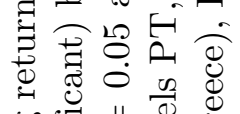
象

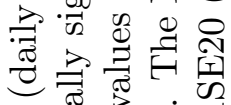
की 曾

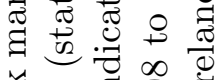
范

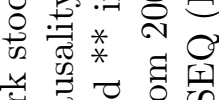

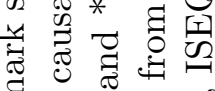

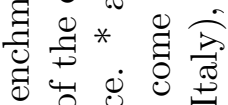

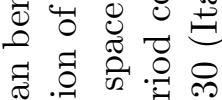

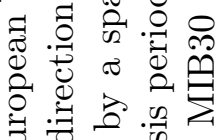

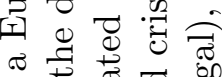
Ð

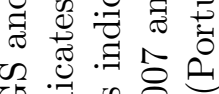
ש ․․

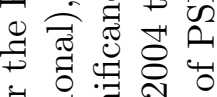

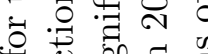

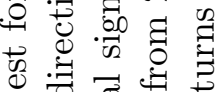

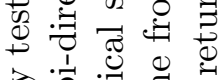
点已.

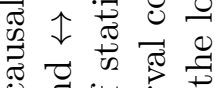

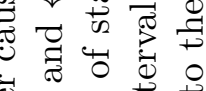
它

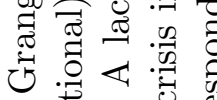

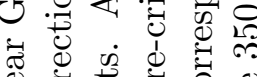

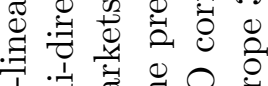

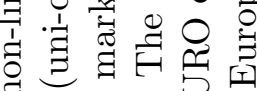

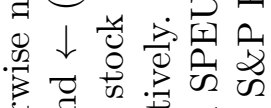

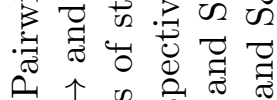

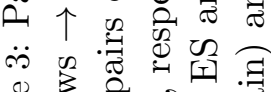

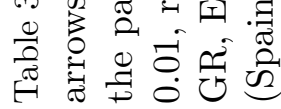



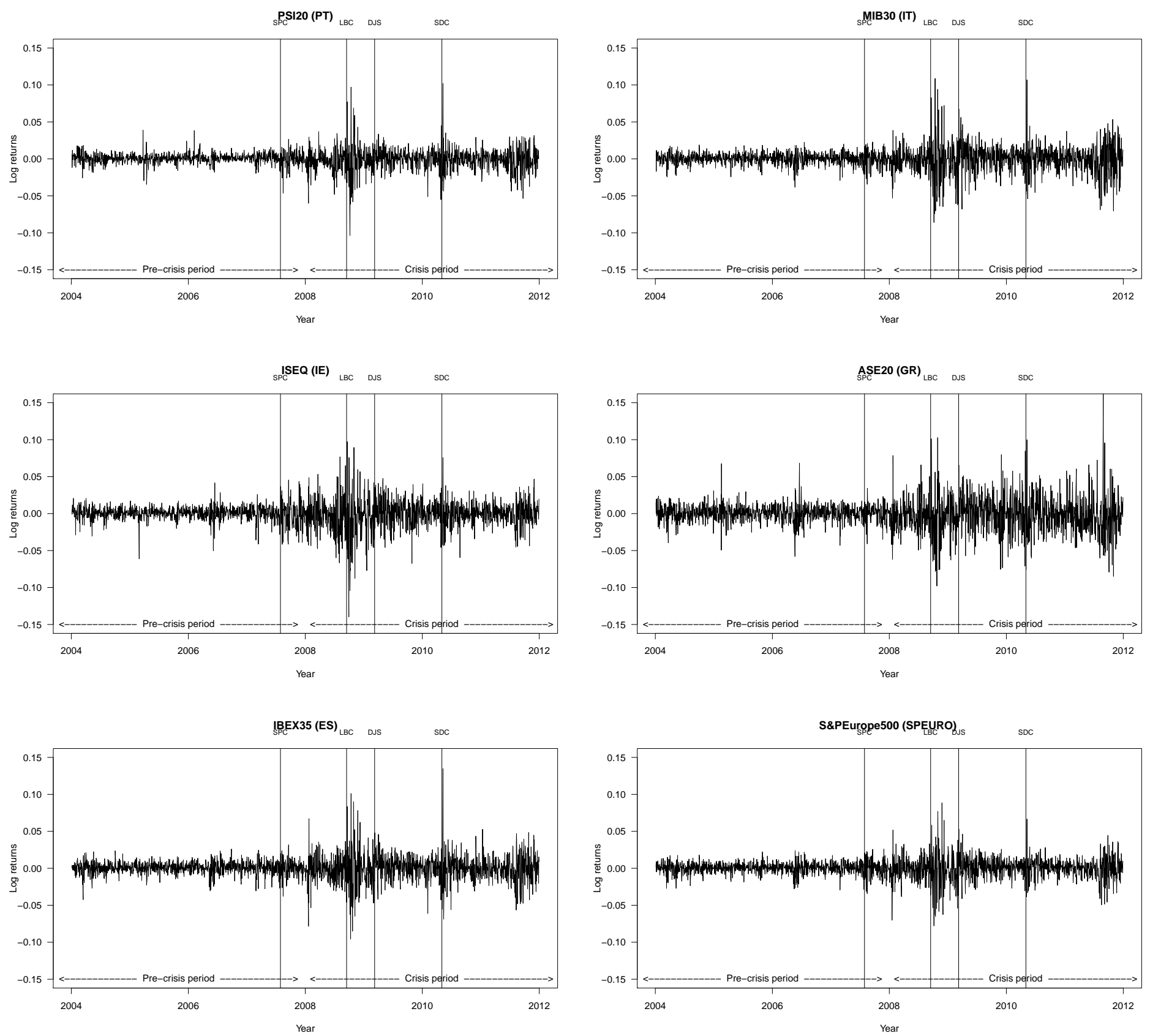

Figure 1: Daily stock market indices (log returns) for the time interval 02/01/2004 - 30/12/2011 (the total number of datapoints is 2086). 


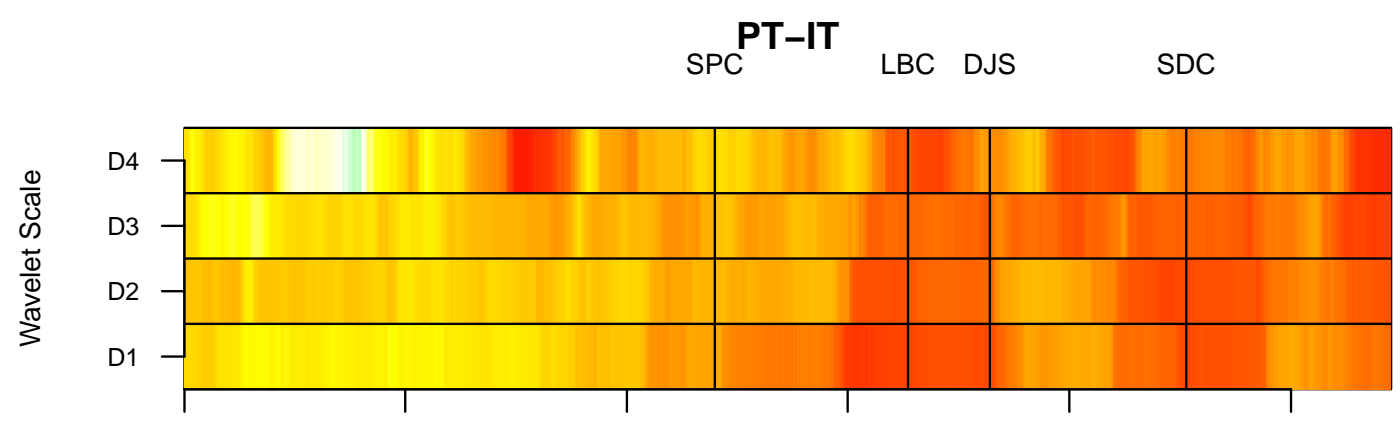

21/06/2004 06/10/2005 23/01/2007 09/05/2008 26/08/2009 13/12/2010
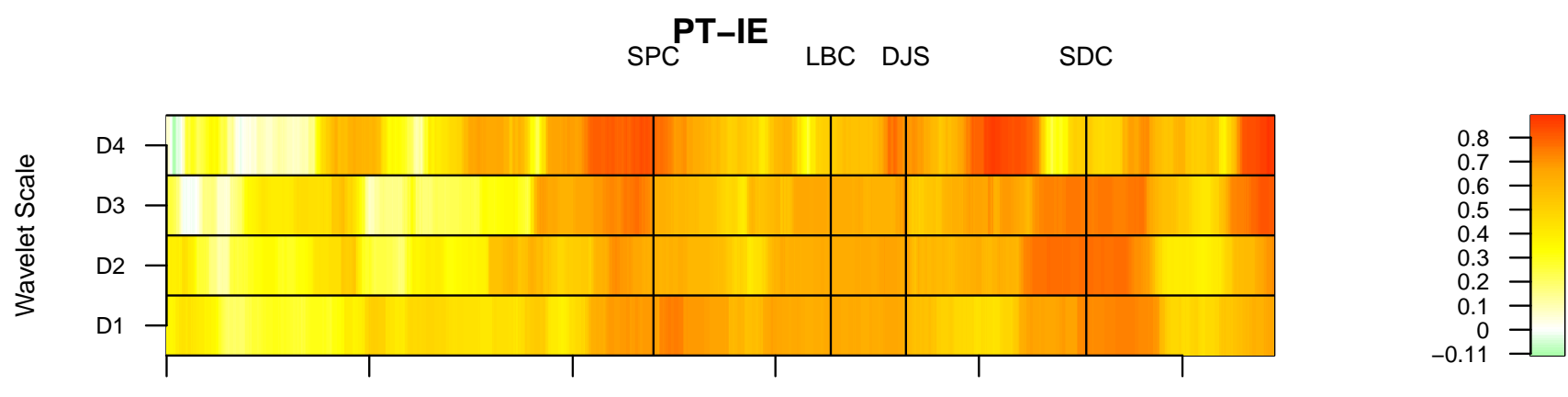

21/06/2004 06/10/2005 23/01/2007 09/05/2008 26/08/2009 13/12/2010
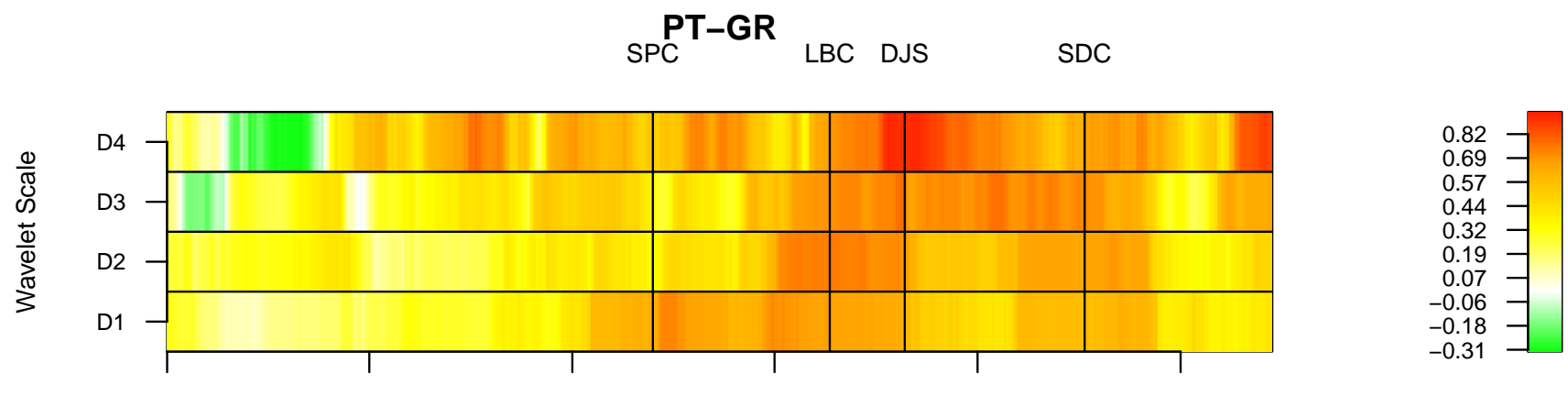

$\begin{array}{lllll}21 / 06 / 2004 & 06 / 10 / 2005 & 23 / 01 / 2007 & 09 / 05 / 2008 & 26 / 08 / 2009\end{array}$

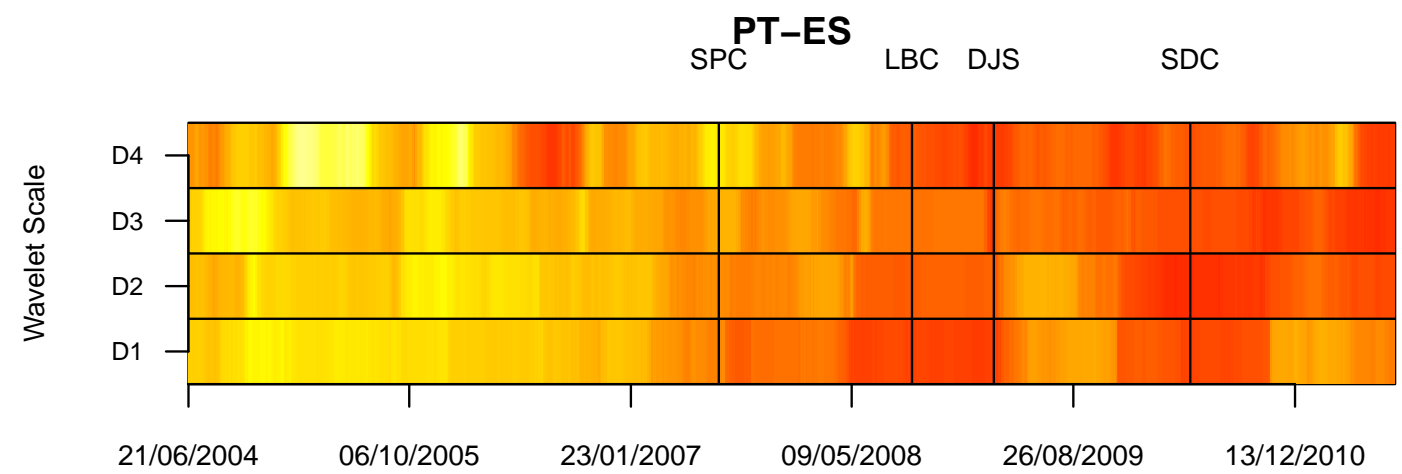



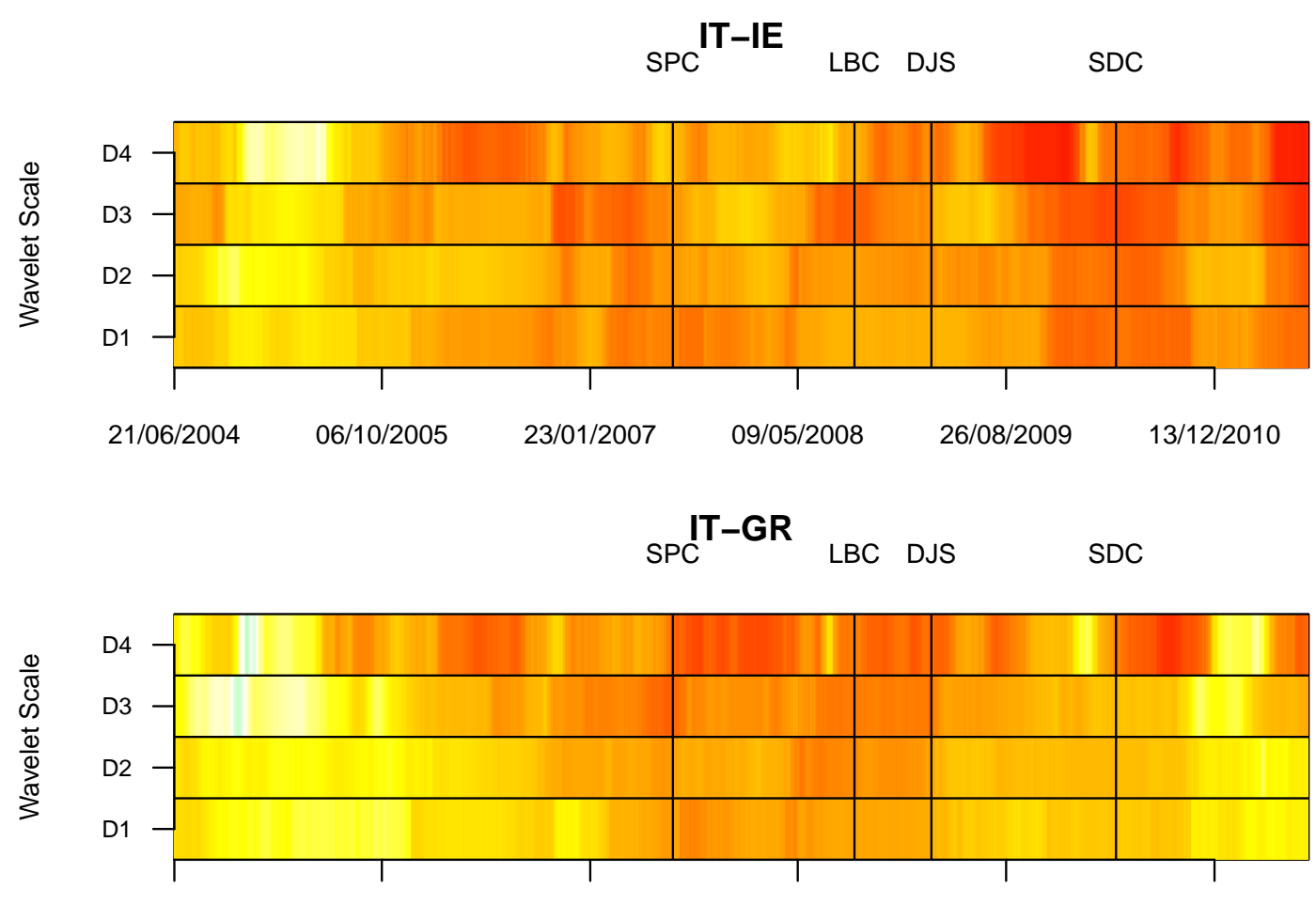

21/06/2004 06/10/2005 26/08/2009 $\quad$ 23/01/2007 $\quad 09 / 12 / 2010$
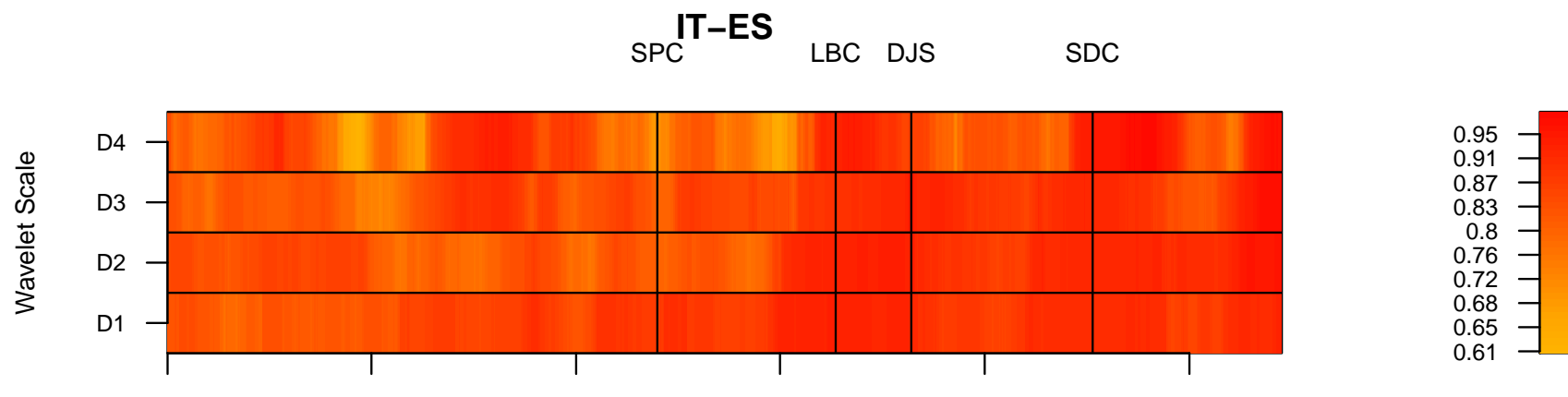

$\begin{array}{lllll}21 / 06 / 2004 & 06 / 10 / 2005 & 23 / 01 / 2007 & 09 / 05 / 2008 & 26 / 08 / 2009\end{array}$

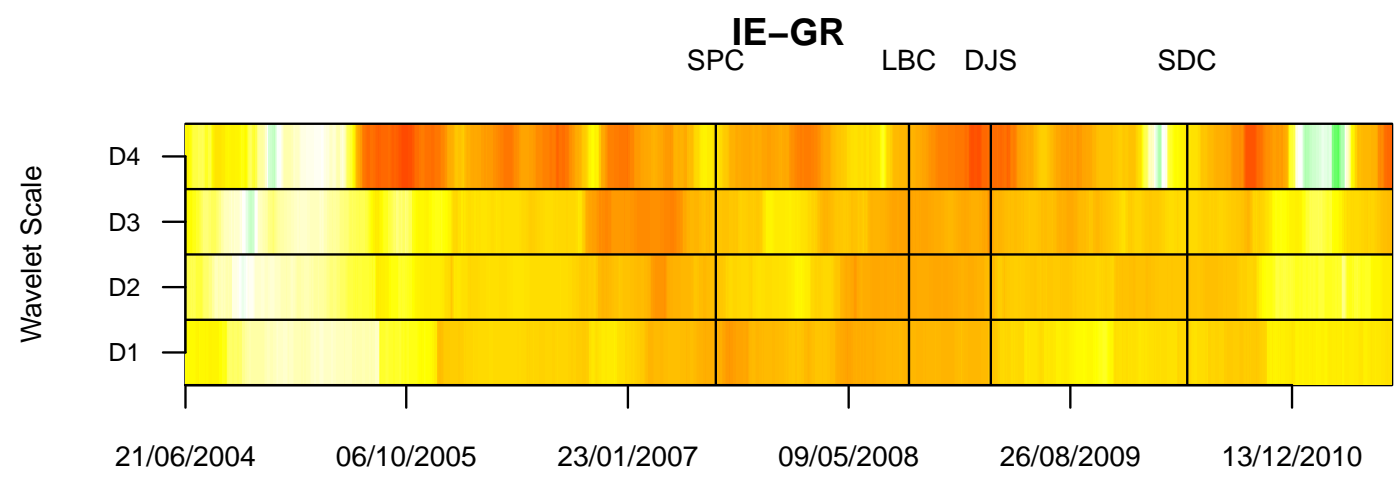




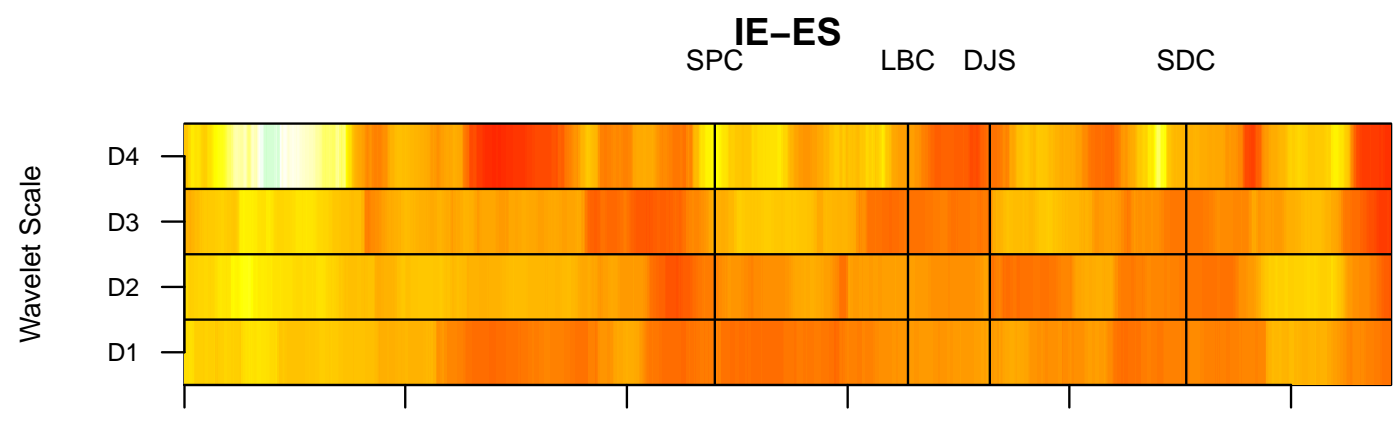

21/06/2004 06 23/01/2007 09/05/2008 26/08/2009 13/12/2010

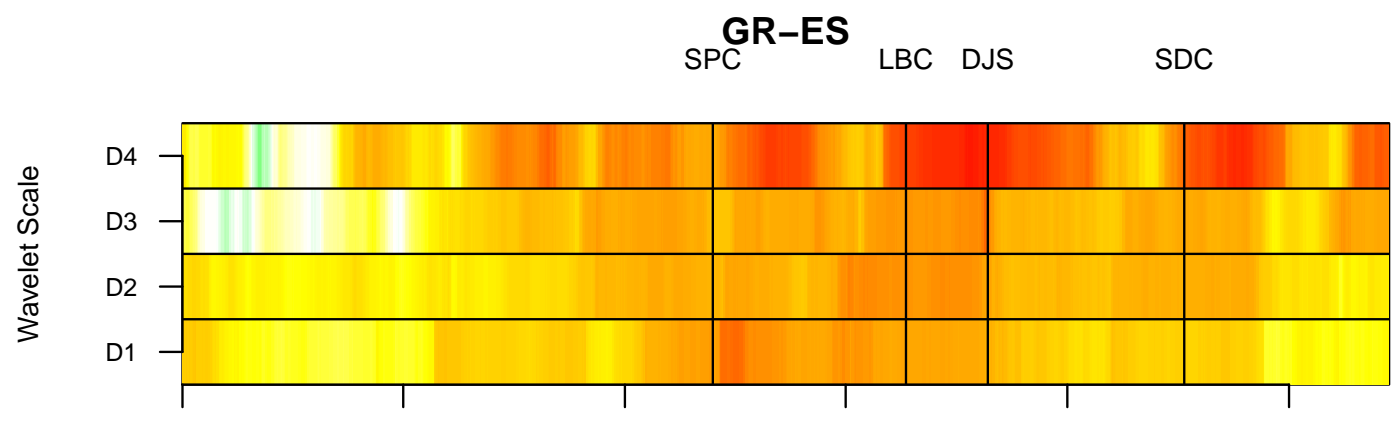

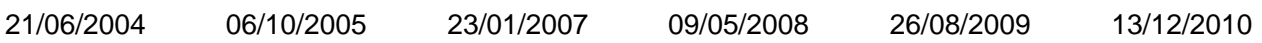

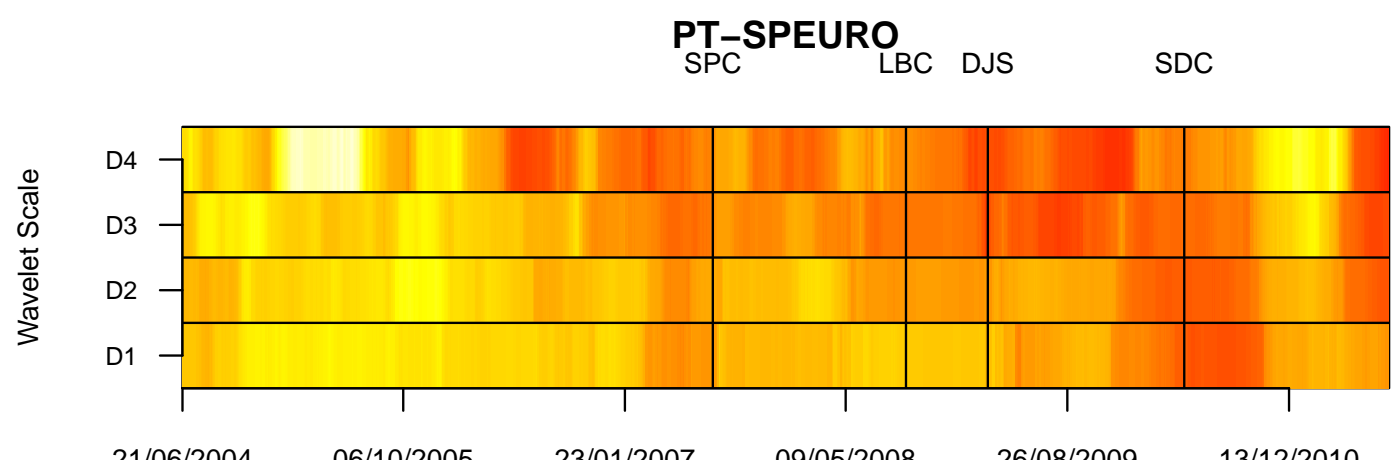

$\operatorname{ITSC}_{\text {SPC }}$ LBC DJS SDC

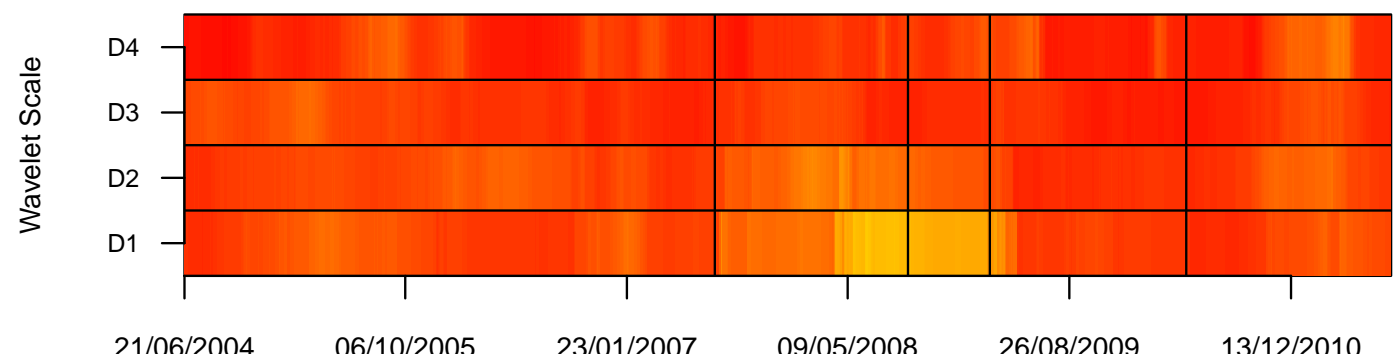

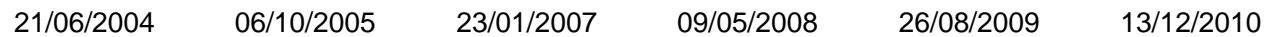



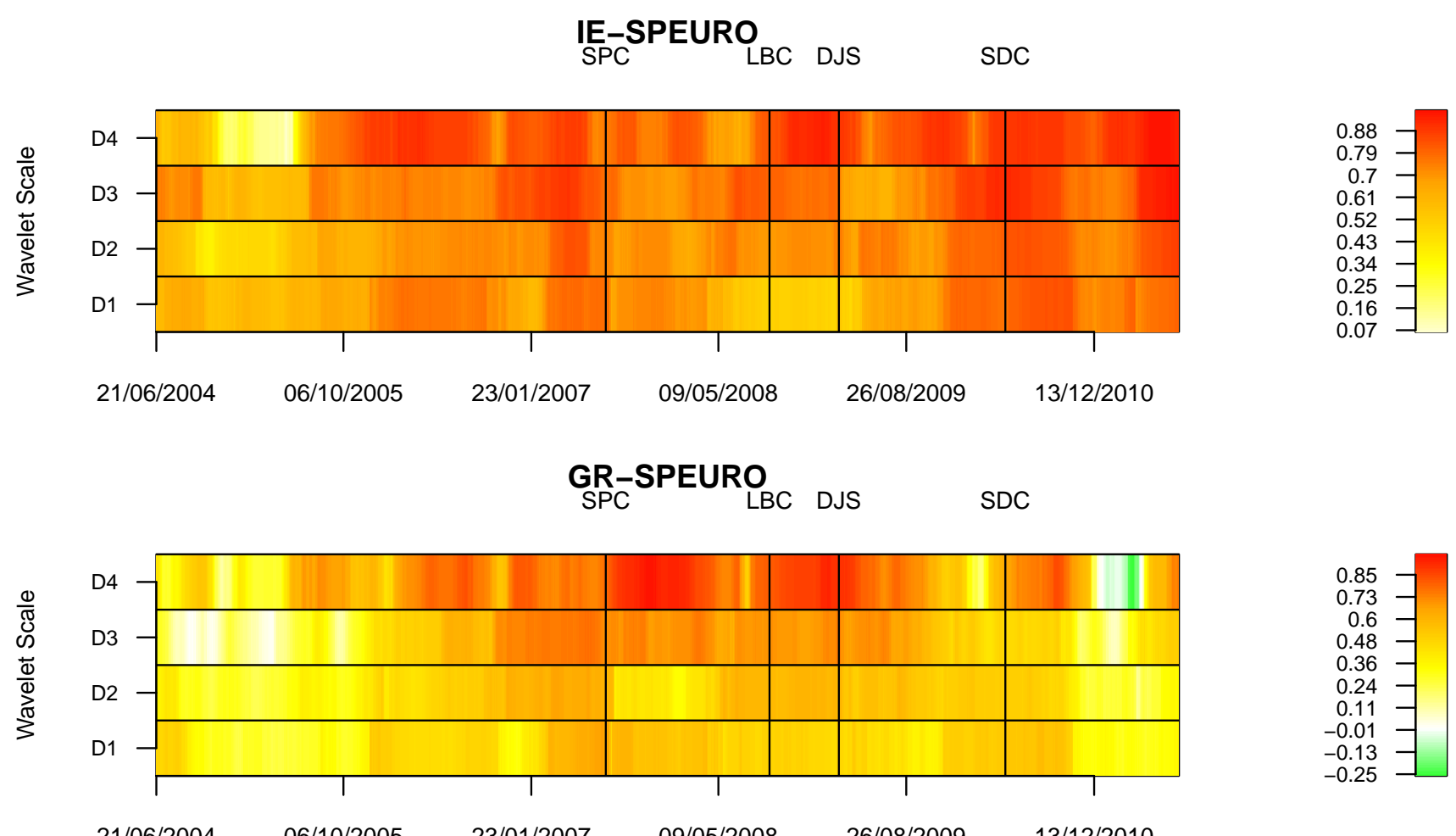

21/06/2004 06/10/2005 23/01/2007 09/05/2008 26/08/2009 13/12/2010

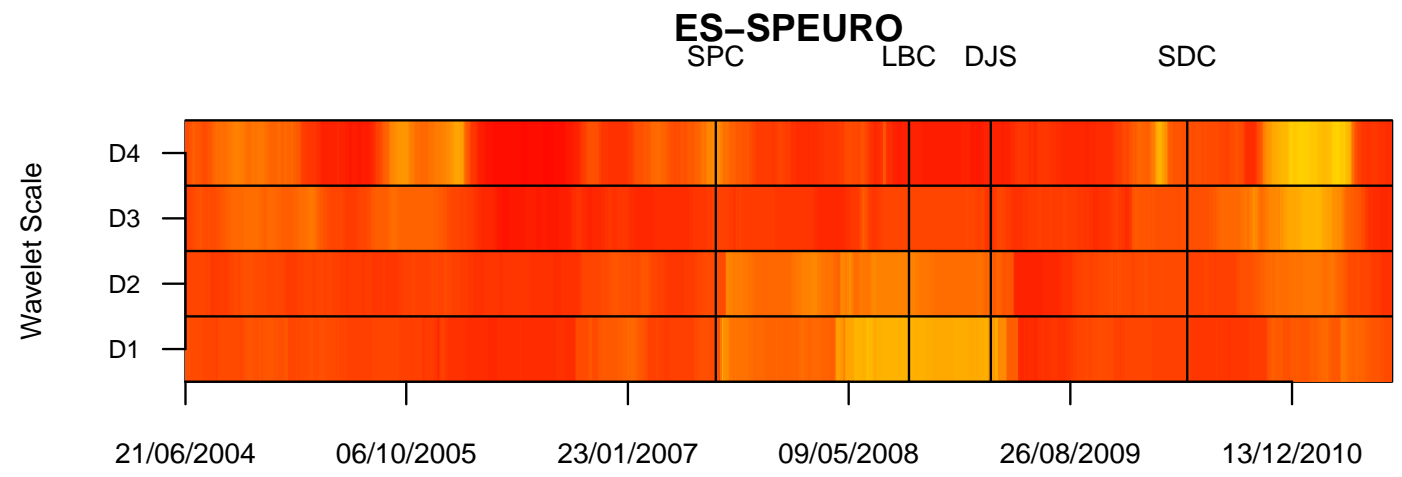

Figure 2: Rolling window (with 250 datapoints) for the pairwise wavelet correlation coefficients for the stock market indices under study. The colour bars represent the wavelet correlations, where the red and blue colours correspond to the highest and lowest wavelet correlation values respectively. The wavelet coefficients are within of the $95 \%$ confidence interval for each wavelet scale. The labels are: start of subprime crisis (SPC), the Lehmann-Brothers collapse (LBC), Dow Jones slump (DJS) and soveriegn debt crisis (SDC). The labels PT, IT, IE, GR, ES and SPEURO correspond to the log returns of PSI20 (Portugal), MIB30 (Italy), ISEQ (Ireland), ASE20 (Greece), IBEX35 (Spain) and SPEURO (S\&P Europe 350). 
Pre-crisis:
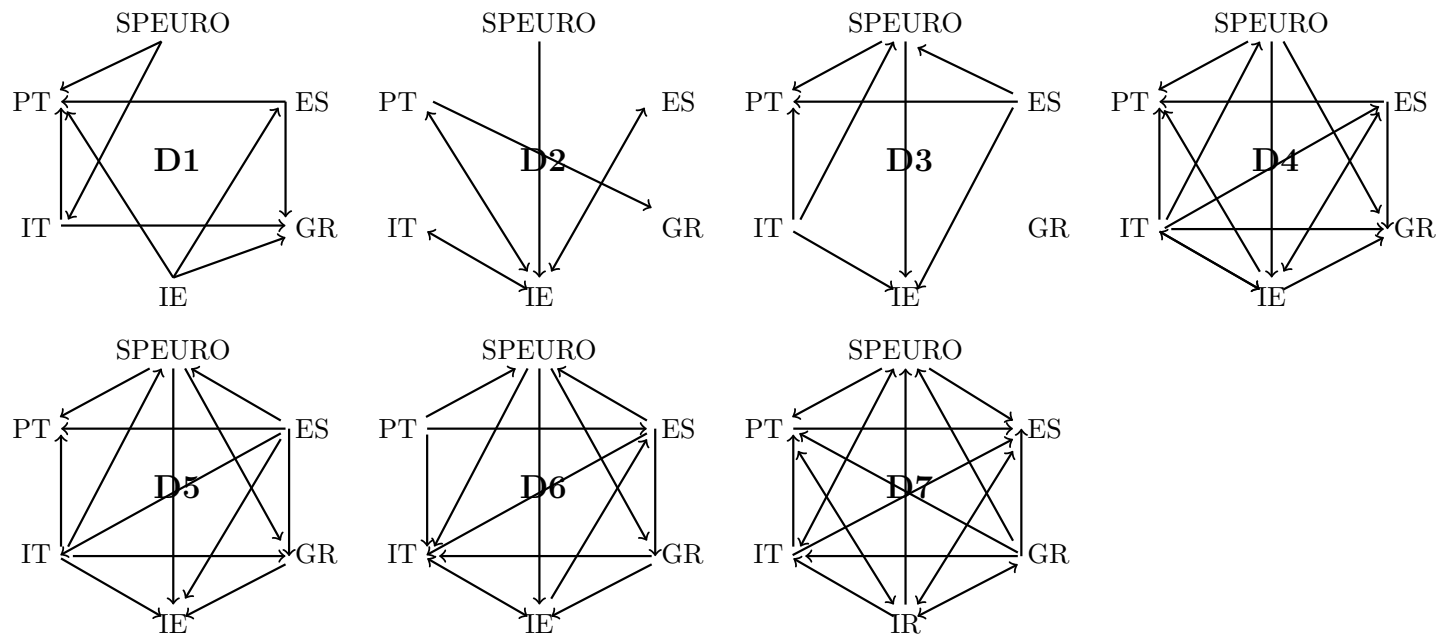

Crisis:
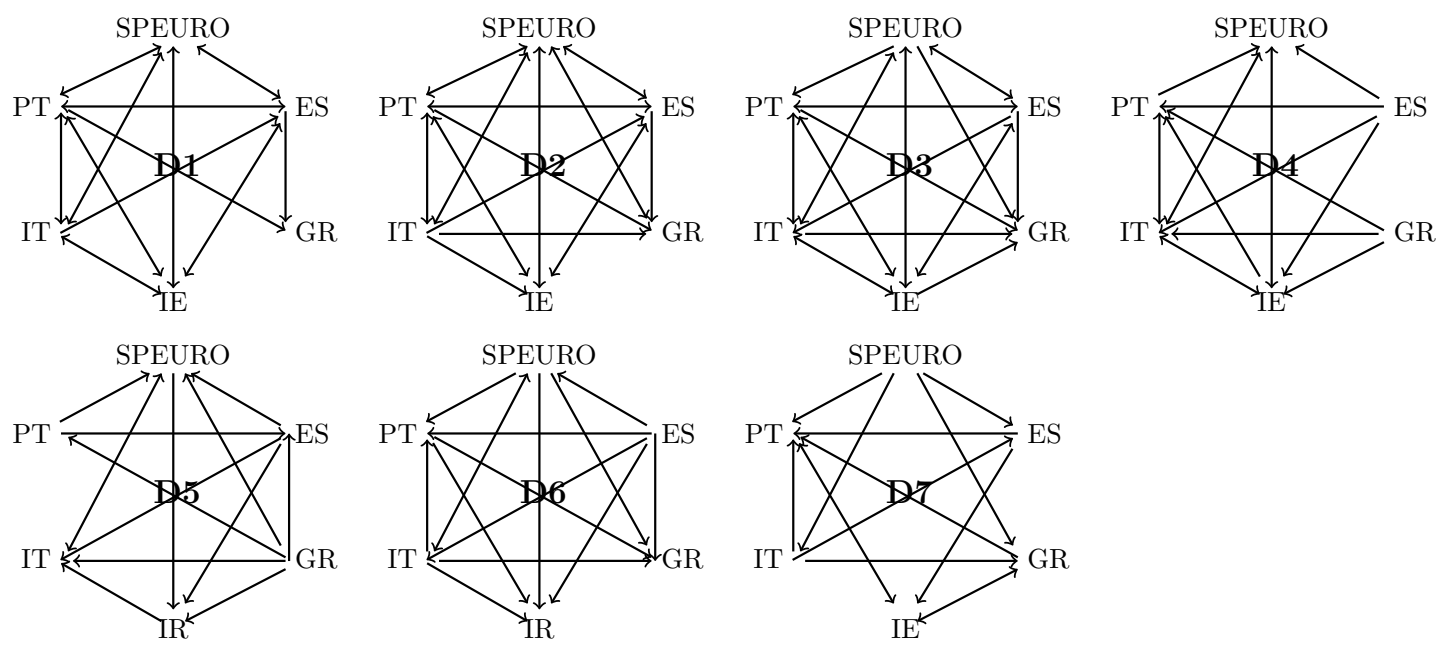

Figure 3: Non-linear Granger causality test for the wavelet coefficients, D1, ..., D7 for the log returns $\left(R_{t}\right)$ of PIIGS and a European benchmark stock markets (SPEURO Europe 350) for the pre-crisis (from 2004 to 2007 ) and crisis periods (from 2008 to 2011). The arrows in the solid lines indicate the causality direction between each stock matket pair with a significance at $5 \%$ level. The labels PT, IT, IE, GR, ES and SPEURO correspond to the log returns of PSI20 (Portugal), MIB30 (Italy), ISEQ (Ireland), ASE20 (Greece), IBEX35 (Spain) and S\&P Europe 350. 
Appendix A. Tables 
苚集

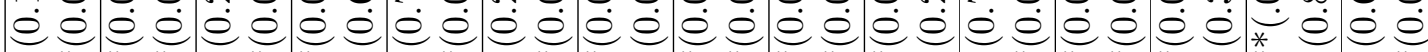

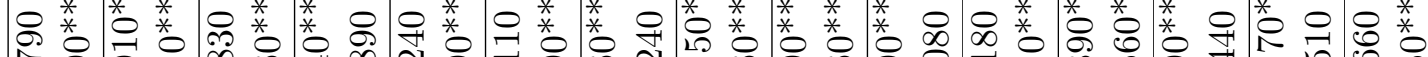

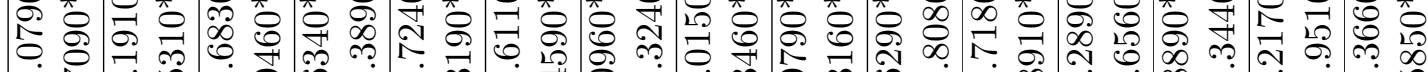

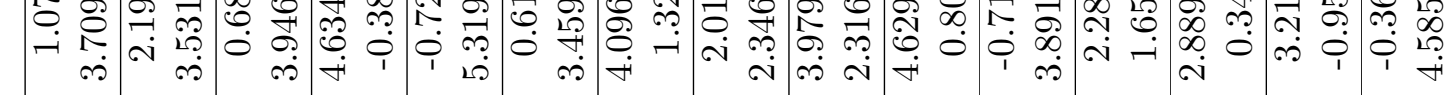

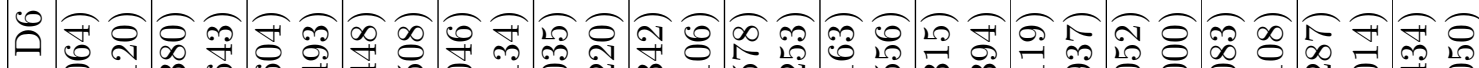

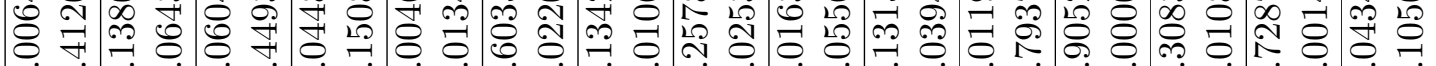
$\dot{e} \dot{e} \dot{e} \dot{e} \dot{e} \dot{e} \dot{e} \dot{e} \dot{e} \dot{e} \dot{e} \dot{e} \dot{e} \dot{e} \dot{e} \dot{e} \dot{e} \dot{e} \dot{e} \dot{e} \dot{e} \dot{e} \dot{e} \dot{e} \dot{e}$ * $\begin{gathered}* \\ * \\ 0\end{gathered}$ 年 (ำ

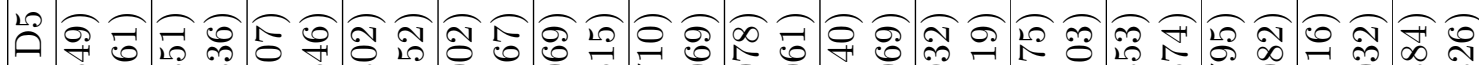
苟

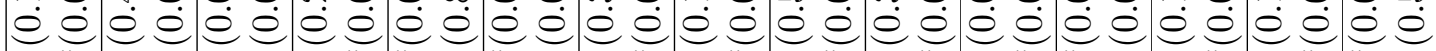
윤 L

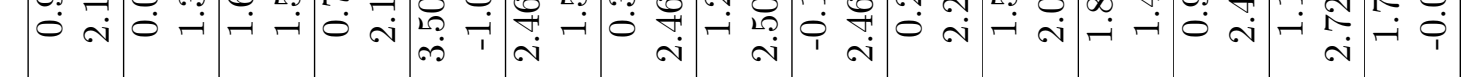

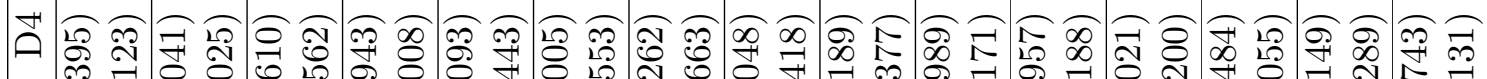

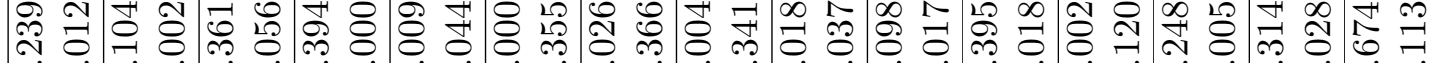

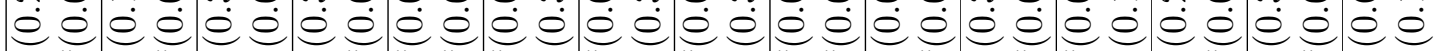

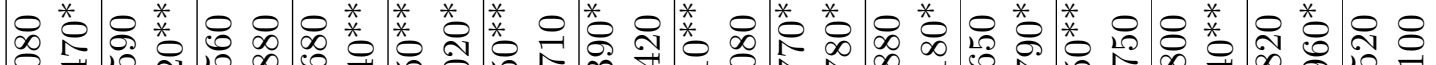

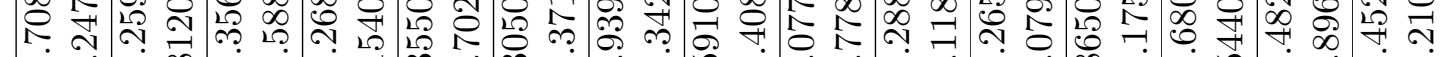

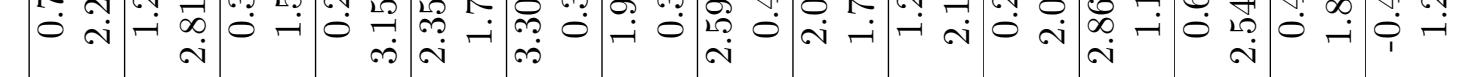

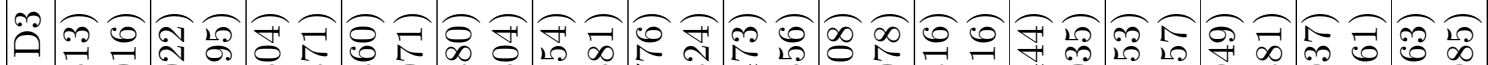
\& 8 :

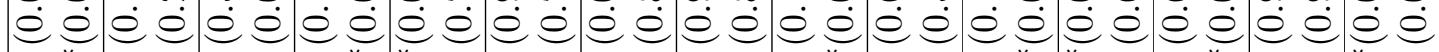

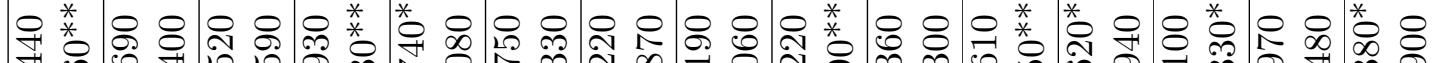
年 윤

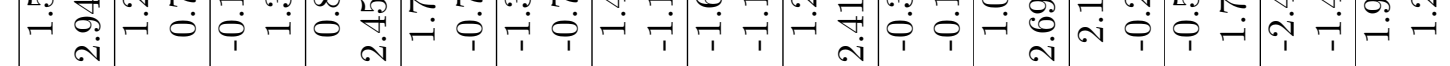

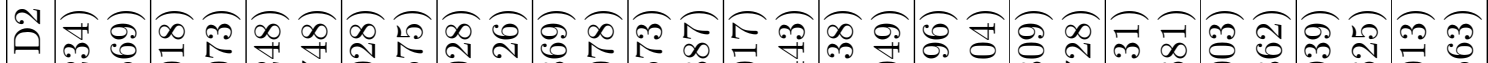

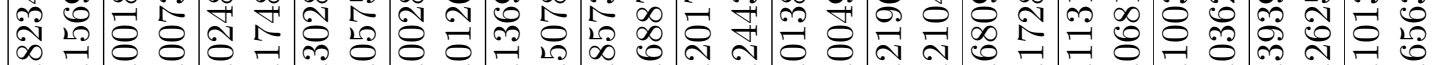

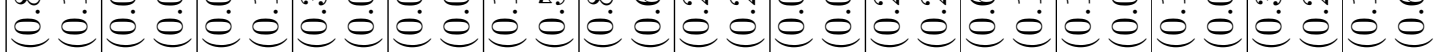

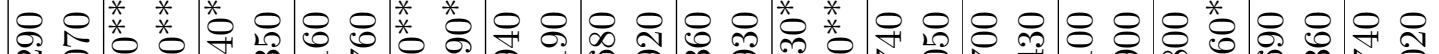
离

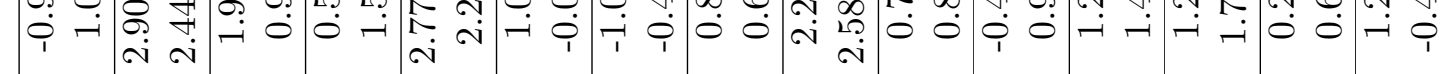

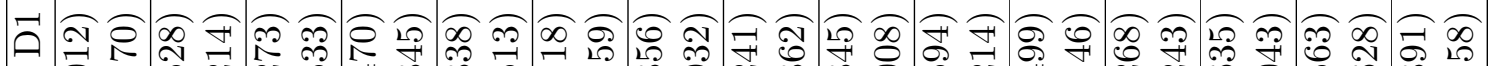

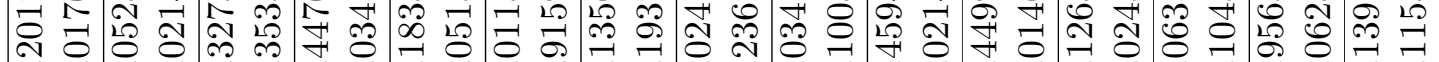

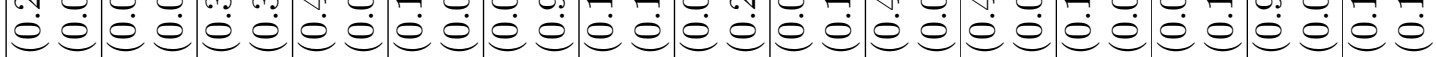

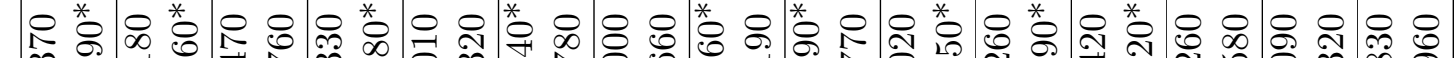

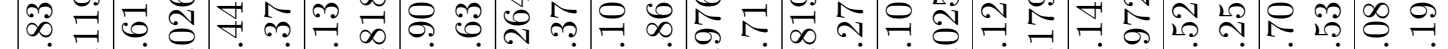

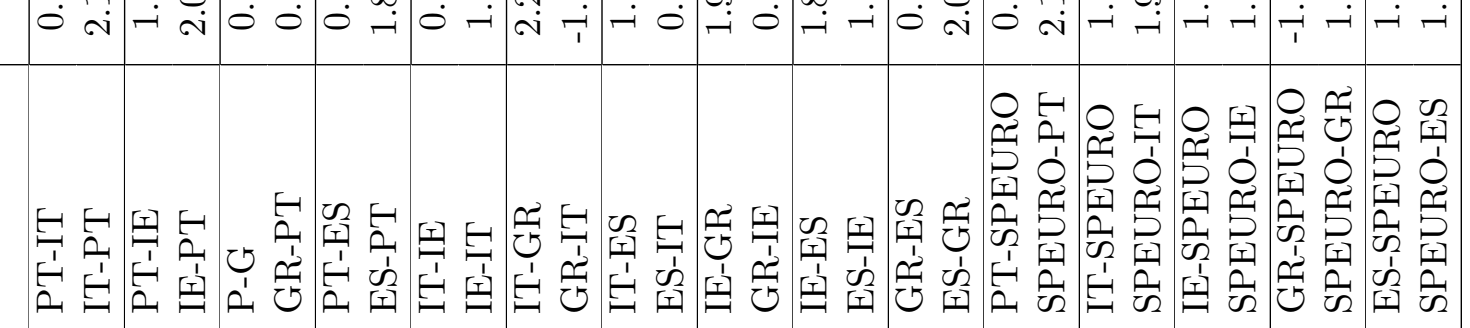

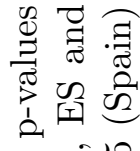
E) 官闹珀 (7) พิ \& (1) $\therefore$ 过 范 ㅇ

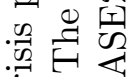
$\dot{0}$ $\overrightarrow{2}$ d $\mp$. 苞矛 号可 . 泉

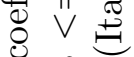
+ o 范 常立 㐘卷 눙 농 궁 प0 $\rightarrow \vee \curvearrowright$ 节记 đن نี สี से 荬 뎽이 *

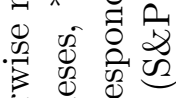
零

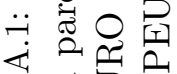
의

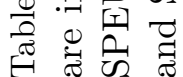




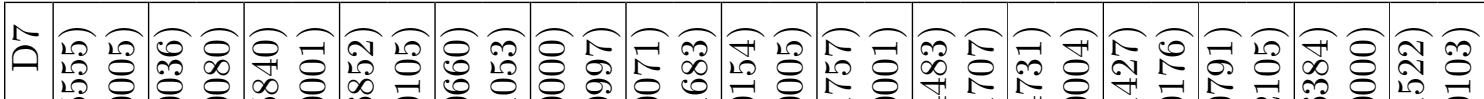
i

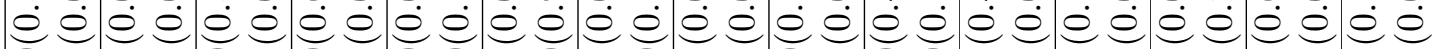

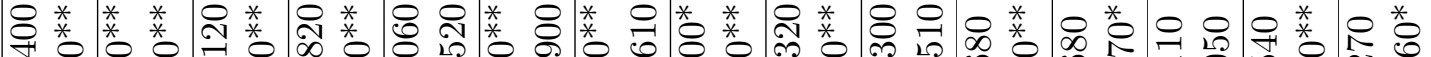

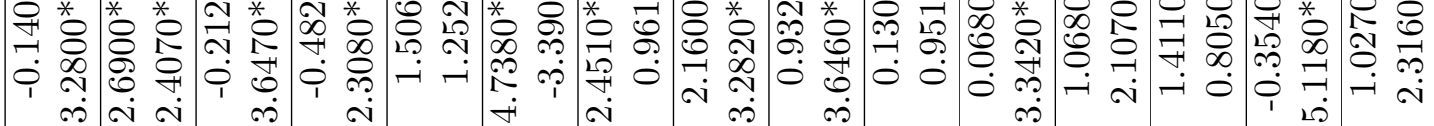

记 定

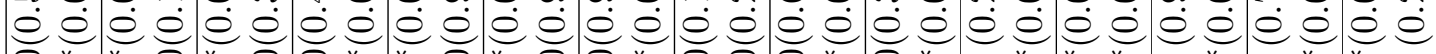

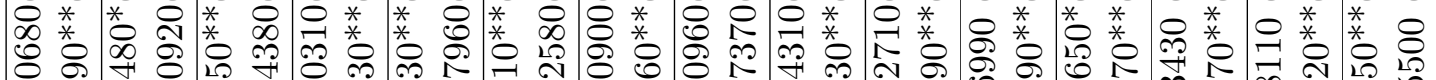

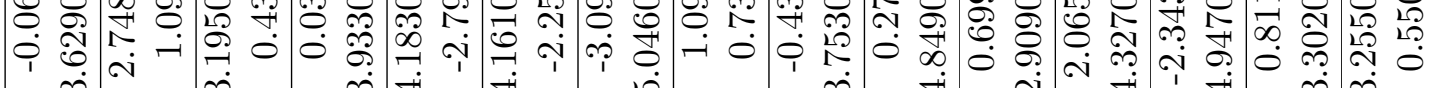

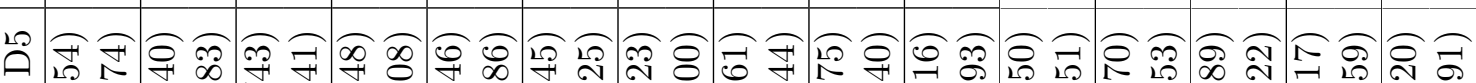

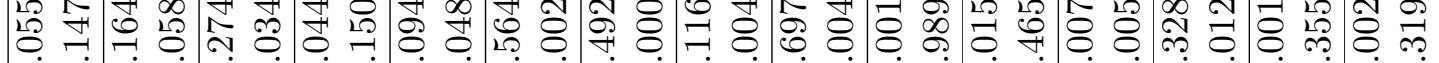

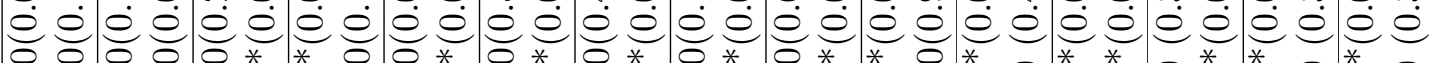

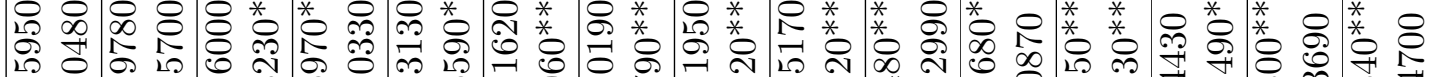

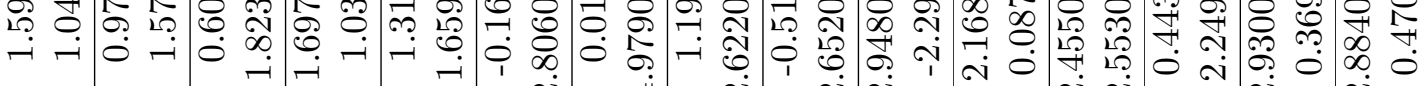

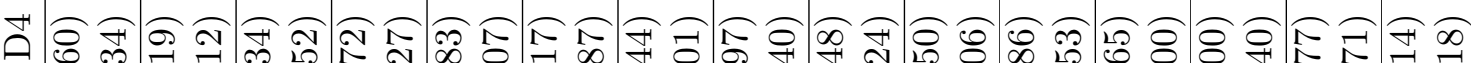
苛

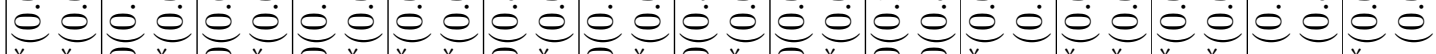

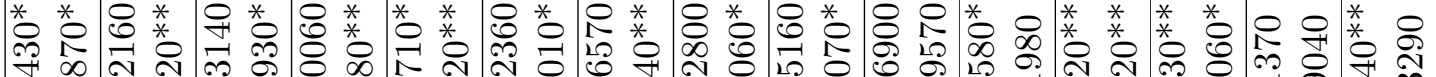
获

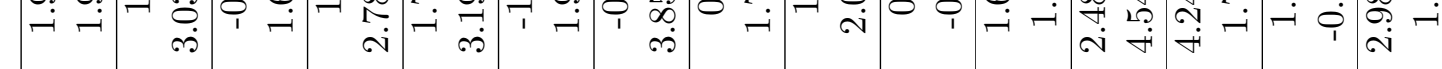

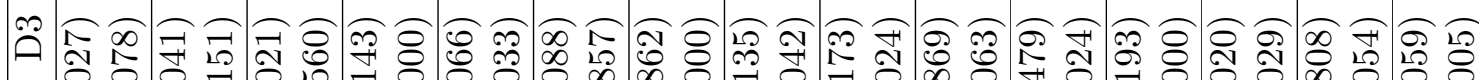

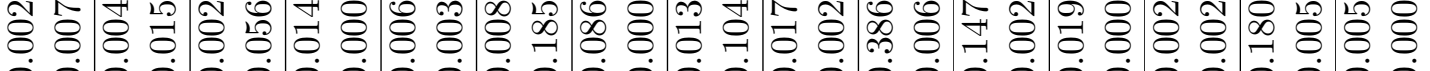

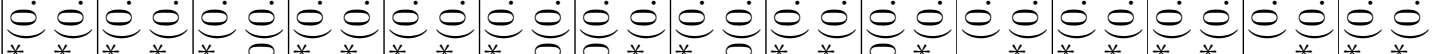

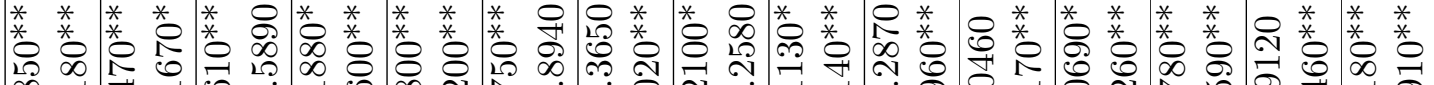

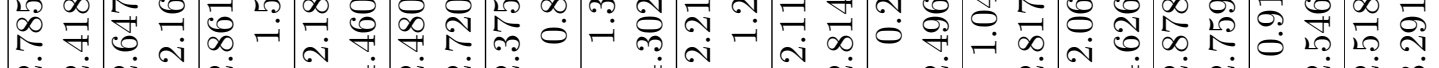

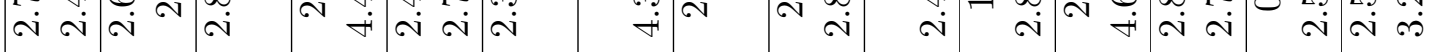

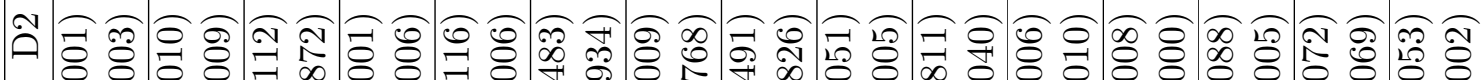
o

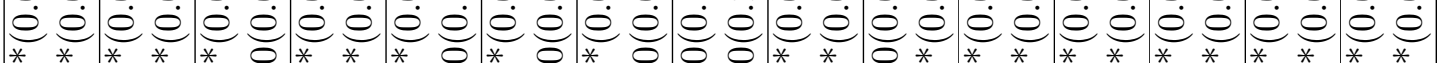

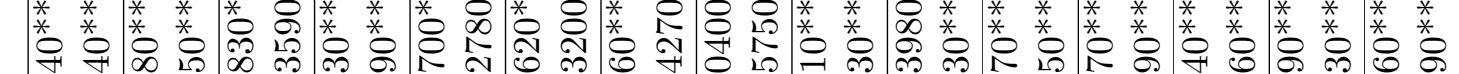

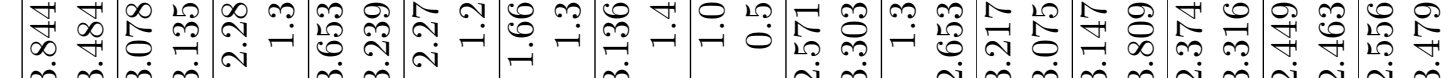

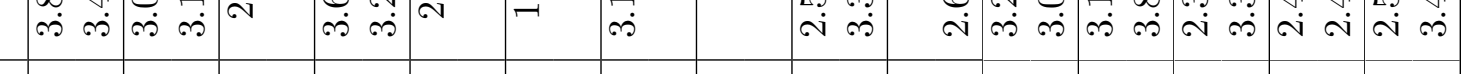

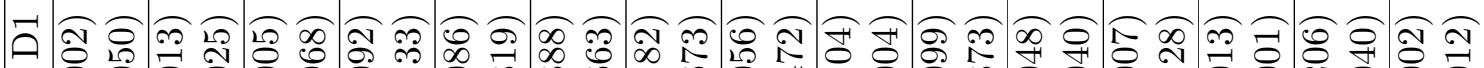
\& 8 :

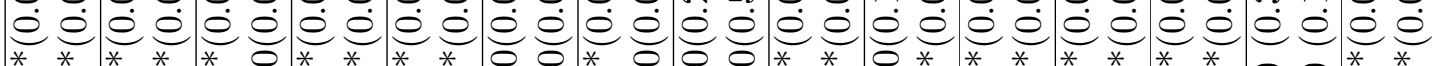

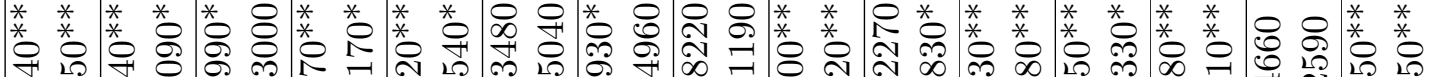

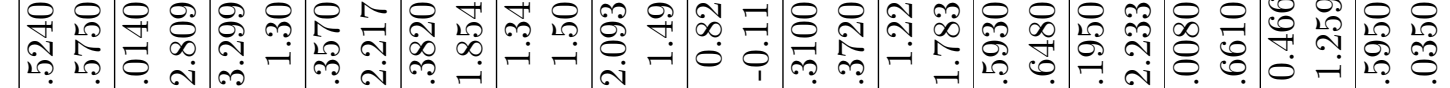

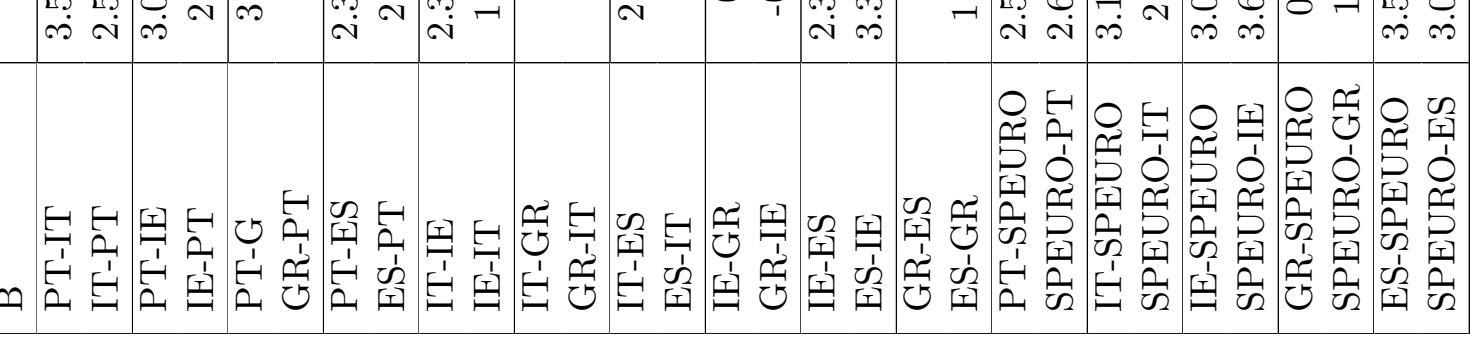

莙 울 过穴穴

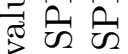
ㄹ. 近设 ㄷํㄹ है

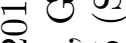
के ᄋํำ 再 .$\dot{0}$ 造 需 \&

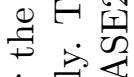
o 8 o द्व 可 iो $+0$ U Z $V$ क वै 耐 +1 贾 ○ी 蔽究 $+20$ 过 苟 $\|$ अ ปี

政产

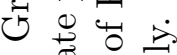

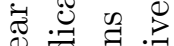
.

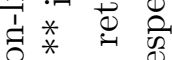
a 0 . 00 0 류으. * कै की 0 $\tau$ 車 $\ddot{\sim}$ 青 य 다윰 0 政

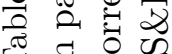

